\title{
Functional Analysis of Plant Defense Suppression and Activation by the Xanthomonas Core Type III Effector XopX
}

\author{
William Stork, Jung-Gun Kim, and Mary Beth Mudgett \\ Department of Biology, Stanford University, Stanford, CA 94305-5020, U.S.A.
}

Submitted 10 September 2014. Accepted 11 November 2014.

\begin{abstract}
Many phytopathogenic type III secretion effector proteins (T3Es) have been shown to target and suppress plant immune signaling but perturbation of the plant immune system by T3Es can also elicit a plant response. XopX is a "core" Xanthomonas T3E that contributes to growth and symptom development during Xanthomonas euvesicatoria infection of tomato but its functional role is undefined. We tested the effect of XopX on several aspects of plant immune signaling. XopX promoted ethylene production and plant cell death (PCD) during $X$. euvesicatoria infection of susceptible tomato and in transient expression assays in Nicotiana benthamiana, which is consistent with its requirement for the development of $X$. euvesicatoriainduced disease symptoms. Additionally, although XopX suppressed flagellin-induced reactive oxygen species, it promoted the accumulation of pattern-triggered immunity (PTI) gene transcripts. Surprisingly, XopX coexpression with other PCD elicitors resulted in delayed PCD, suggesting antagonism between XopX-dependent PCD and other PCD pathways. However, we found no evidence that XopX contributed to the suppression of effector-triggered immunity during $X$. euvesicatoria-tomato interactions, suggesting that XopX's primary virulence role is to modulate PTI. These results highlight the dual role of a core Xanthomonas T3E in simultaneously suppressing and activating plant defense responses.
\end{abstract}

Phytopathogenic bacteria of the genus Xanthomonas cause disease in diverse crop systems worldwide. Xanthomonas euvesicatoria (formerly $X$. campestris pathovar vesicatoria) (Jones et al. 2004) causes bacterial spot disease in tomato (Solanum lycopersicum) and pepper (Capsicum annuum) (Jones et al. 1998). During infection of susceptible plants, X. euvesicatoria infiltrates the apoplastic space of foliar tissue through natural openings or wounds and multiplies rapidly there. $X$. euvesicatoria utilizes type III secretion (T3S) to translocate type III effector proteins (T3Es) directly into the hosts' cells (Buttner 2012), and functional T3S is required for maximal $X$. euvesicatoria growth in its hosts (Bonas et al. 1991). Genomic analyses have identified nine "core" T3Es that are found in almost all sequenced Xanthomonas strains (Hajri et al. 2009; Jalan et al. 2011; Moreira et al. 2010; Potnis et al. 2011). The

Corresponding author: M. B. Mudgett; Telephone: +1.650 .723 .3252 ; Fax: +1.650 .723 .6132 ; E-mail: mudgett@ stanford.edu

* The $\boldsymbol{e}$-Xtra logo stands for "electronic extra" and indicates that a supplementary figure is published online.

(C) 2015 The American Phytopathological Society conservation of these core T3Es suggest that they serve a critical role in Xanthomonas pathology, and insight gained by the study of these core T3Es may aid in the development of disease mitigation strategies (Dangl et al. 2013; Potnis et al. 2011).

XopX is one such core T3E. It was originally identified in a screen of $X$. euvesicatoria genes that conferred the ability to cause plant cell death (PCD) in Nicotiana benthamiana to the non-PCD-eliciting bacterium $X$. campestris pv. campestris 8004 (Metz et al. 2005). XopX is delivered into the plant cell by $\mathrm{T} 3 \mathrm{~S}$ and required for full virulence of $X$. euvesicatoria GM98-38 on tomato and pepper (Metz et al. 2005). Despite the ability of XopX to elicit PCD in N. benthamiana when delivered by bacteria, transgenic $N$. benthamiana expressing XopX are viable, more susceptible to Xanthomonas and Pseudomonas spp., and develop more severe symptoms during infection (Metz et al. 2005). This suggests that XopX elicitation of PCD is linked to its virulence activity rather than evidence of avirulence activity. Although XopX's function in the plant cell during infection is unknown, its ortholog from $X$. oryzae pv. oryzae was recently shown to suppress $X$. oryzae pv. oryzae LipA-elicited callose deposition in rice (Sinha et al. 2013). This latter evidence suggests that XopX may contribute to bacterial virulence by suppressing plant immune signaling. Given that XopX is cytotoxic when expressed in yeast (Salomon et al. 2011), it is likely that XopX targets a broadly conserved eukaryotic cell process that is required for viability.

We are interested in identifying a specific role for XopX in $X$. euvesicatoria pathogenesis. Like many phytopathogenic bacteria, $X$. euvesicatoria maintains a hemibiotrophic lifestyle that requires the pathogen to suppress or evade plant defense responses but avoid killing its host at early stages of infection (Doidge 1921). During infection, the detection of conserved microbe-associated molecular patterns (MAMPs) such as bacterial flagellin by plant cell surface receptors elicits a limited plant defense response called pattern-triggered immunity (PTI) (Jones and Dangl 2006). It is well known that phytopathogenic bacteria employ T3Es to suppress PTI (Boller and He 2009). In response, plants exploit the pathogen's requirement of a living host by activating PCD during effector-triggered immunity (ETI), an elevated defense response elicited when plant disease resistance proteins detect the presence or activity of specific T3Es (Spoel and Dong 2012). However, T3Es can also suppress ETI (Jones and Dangl 2006). Thus, the interaction between T3Es and the plant immune system is complex and multilayered, and the specific combination of T3Es deployed by the pathogen is a critical determinant of the outcome of a plant-pathogen interaction.

In addition to its role during ETI in resistant plants, PCD leads to host tissue necrosis, which is a symptom and eventual outcome of disease caused by hemibiotrophic pathogens in susceptible plants. The regulation of this PCD (by host or patho- 
gen) is not well understood (Badel et al. 2006; Cohn and Martin 2005; del Pozo et al. 2004). In tomato, the phytohormones salicylic acid (SA) and ethylene (ET) are critical, positive regulators of $\mathrm{PCD}$ and symptom development that occurs during infection by $X$. euvesicatoria and Pseudomonas syringae pv. tomato DC3000 (Cohn and Martin 2005; Lund et al. 1998; O'Donnell et al. 2001, 2003). Our previous work revealed that $X$. euvesicatoria employs the T3E XopD as a "tolerance factor" to suppress SA- and ET-dependent defense and symptom development in tomato (Kim et al. 2008, 2013). The T3E XopJ was also shown to suppress SA accumulation, resulting in the delay of tissue senescence during $X$. euvesicatoria infection of pepper (Ustun et al. 2013). By contrast, the T3Es AvrPto and AvrPtoB are responsible for activating ET production during $P$. syringae pv. tomato infection of tomato, which affects symptom development (Cohn and Martin 2005). Currently, it is not known whether individual $X$. euvesicatoria T3Es are also responsible for promoting ET or SA production.

In this study, we focused on assessing the role of XopX in regulating $\mathrm{PCD}$, manipulating phytohormone signaling, and suppressing immunity during PTI and ETI. These three critical functions help to distinguish the role that individual T3Es play within the context of a given T3E repertoire (Cunnac et al. 2009). We provide evidence that XopX contributes to X. euvesicatoria virulence by suppressing specific aspects of plant immunity (i.e., reactive oxygen species [ROS] accumulation) but simultaneously activates plant defense responses and PCD. A similar pattern of dual behavior (i.e., suppression of plant immunity coupled to activation of plant defense and PCD) was previously identified for the $P$. syringae pv. tomato core T3E AvrE1 and led to the model that plants can respond to T3E virulence function with a "default to death and defense" strategy (Badel et al. 2006; Lindeberg et al. 2012). Our results for XopX provide further support for this model and highlight important considerations for evaluating how individual T3Es contribute to the outcome of plant-microbe interactions.

\section{RESULTS}

\section{Confirmation of XopX contribution}

to $X$. euvesicatoria virulence using $X$. euvesicatoria 85-10.

The contribution of XopX to X. euvesicatoria growth in tomato and pepper was previously demonstrated using $X$. euvesicatoria GM98-38 (Metz et al. 2005). In order to take advantage of the genome sequence and annotation of $X$. euvesicatoria 85-10 during our study of XopX (Thieme et al. 2005), we used an $X$. euvesicatoria $85-10$ strain with a genomic deletion in the xopX coding sequence $(\Delta x o p X)$ (Sonnewald et al. 2012). Consistent with prior work, $\Delta x o p X$ grew less and caused reduced leaf chlorosis and necrotic spots during infection of 'VF36' tomato, which is susceptible to $X$. euvesicatoria 85-10 (Supplementary Fig. S1A and B). We genetically com-

Table 1. Bacterial strains and plasmids used

\begin{tabular}{|c|c|c|}
\hline Strain or plasmid & Relevant characteristics $^{\mathbf{a}}$ & Source or reference \\
\hline \multicolumn{3}{|l|}{ Bacteria } \\
\hline \multicolumn{3}{|l|}{ Xanthomonas euvesicatoria } \\
\hline Wild-type & Strain 85-10; Rif $^{\mathrm{r}}$ & $\begin{array}{l}\text { Minsavage et al. } 1990 \text {; } \\
\text { Thieme et al. } 2005\end{array}$ \\
\hline$\Delta x о p X$ & Strain 85-10; deletion in $x o p X ;$ Rif $^{\mathrm{r}}$ & Sonnewald et al. 2012 \\
\hline$\Delta h r c V$ & Strain 85-10; deletion in $h r c V$; Rif $^{\mathrm{T}}$ & Rossier et al. 1999 \\
\hline$\Delta a v r R x v$ & Strain 85-10; deletion in avrRxv; $\operatorname{Rif}^{\mathrm{T}}$ & This work \\
\hline$\Delta x o p X \Delta a v r R x v$ & Derived from $\Delta x o p X$; deletion in $a v r R x v ;$ Rif $^{\mathrm{r}}$ & This work \\
\hline \multicolumn{3}{|c|}{ Pseudomonas syringae pv. tomato } \\
\hline$\Delta h r c U$ & Strain DC3000; deletion in $h r c U$; $\operatorname{Rif}^{r}$ & Mudgett and Staskawicz 1999 \\
\hline \multicolumn{3}{|l|}{ Agrobacterium tumefaciens } \\
\hline $\mathrm{C} 58 \mathrm{C} 1, \mathrm{pCH} 32$ & C58 with Ti plasmid cured; $\mathrm{pCH} 32$ is derivative of $\mathrm{pCC} 113$ with $\operatorname{virE} ; \operatorname{Rif}^{\mathrm{r}} \mathrm{Tet}^{\mathrm{r}}$ & Tai et al. 1999 \\
\hline EHA105 & C58 with pEHA105 (pTiBo542 $\Delta$ T-DNA); Rif ${ }^{\mathrm{T}}$ & Hood et al. 1993 \\
\hline GV2260 & C58 with pGV2260 (pTiB6S3 4 T-DNA); Rif ${ }^{\mathrm{T}}$ & McBride and Summerfelt 1990 \\
\hline \multicolumn{3}{|l|}{ Escherichia coli } \\
\hline DH5 $\alpha$ & $\begin{array}{l}\mathrm{F}-80 \mathrm{~d} l a c Z \Delta \mathrm{M} 15 \Delta(\text { lacZYA-argF }) U 169 \text { endA1 deoR recAl hsdR17(rK- mK+) } \\
\text { phoA supE44 } \lambda \text {-thi-l gyrA96 relA1 }\end{array}$ & Life Technologies, Carlsbad, CA \\
\hline HB101, pRK600 & $\begin{array}{l}\left.\text { F- } \Delta(\text { gpt-proA }) 62 \text { leuB6glnV44 ara-14 galK2 lacY1 (mcrC-mrr) rpsL20 } \mathrm{Str}^{\mathrm{r}}\right) \text { xyl-5 } \\
m t l-1 \text { recA13 thi-1; pRK600 is } \mathrm{Cmp}^{\mathrm{R}} \text { derivative of RK2013 }\end{array}$ & Kessler et al. 1992 \\
\hline \multicolumn{3}{|c|}{ - } \\
\hline ADPWH_lux & Insertion of luxCDABE between salA and salR & Huang et al. 2005 \\
\hline \multicolumn{3}{|c|}{ 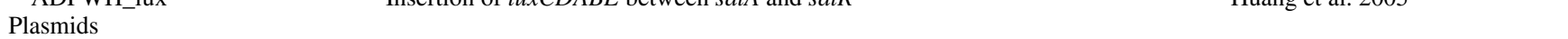 } \\
\hline $\mathrm{pCR} 8 / \mathrm{GW} / \mathrm{TOPO}$ & $\mathrm{Spc}^{\mathrm{r}}$ & Life Technologies, Carlsbad, CA \\
\hline pJET1.2/blunt & $\mathrm{Amp}^{\mathrm{r}}$ & Thermo Scientific, Waltham, MA \\
\hline pDEST17 & $\mathrm{Amp}^{\mathrm{r}}$ & Life Technologies, Carlsbad, CA \\
\hline pDEST17 $(x o p X)$ & pDEST17 with $x o p X$ fusion to N-terminal $6 \mathrm{xHis}$ tag; $\mathrm{Amp}^{\mathrm{r}}$ & \\
\hline pLVC18-RfC & Gateway destination suicide vector; Tet $^{r}$ & Roden et al. 2004 \\
\hline pLVC18-RfC $(\Delta a v r R x v)$ & $\begin{array}{l}\text { pLVC18 derivative with fusion of genomic regions upstream and downstream of } \\
\text { avrRxv; } \text { Tet }^{r}\end{array}$ & This work \\
\hline pDSK519 & $\mathrm{Kan}^{\mathrm{r}}$ & Keen et al. 1988 \\
\hline pDSK519(xop $\left.X_{2623}\right)$ & pDSK519 with $x o p X$ including upstream and downstream regions; Kan ${ }^{\mathrm{r}}$ & This work \\
\hline pGWB6 & $\mathrm{Kan}^{\mathrm{r}}$ & Nakagawa et al. 2007 \\
\hline pGWB6 $6(x о p X)$ & pGWB6 with $x o p X$ and $35 S$ promoter; $\mathrm{Kan}^{\mathrm{r}}$ & This work \\
\hline pBTEX & $\mathrm{Kan}^{\mathrm{r}}$ & Frederick et al. 1998 \\
\hline pBTEX (Pto; avrPto) & pBTEX with Pto and avrPto, both with $35 S$ promoter; $\mathrm{Kan}^{\mathrm{r}}$ & Frederick et al. 1998 \\
\hline pBTEX $($ Bax $)$ & pBTEX with Bax and $35 S$ promoter; Kan ${ }^{\mathrm{r}}$ & G. Sessa \\
\hline pER8 & $\mathrm{Spc}^{\mathrm{r}}$ & Zuo et al. 2000 \\
\hline pER8(SIMKKKa) & pER8 with Spc ${ }^{r}$ & G. Sessa \\
\hline $\mathrm{pER} 8\left(\mathrm{~S} 1 M K K 2^{D D}\right)$ & $\mathrm{Spc}^{\mathrm{r}}$ & G. Sessa \\
\hline $\mathrm{pER} 8(\mathrm{~S} 1 M P K 1)$ & $\mathrm{Spc}^{\mathrm{r}}$ & G. Sessa \\
\hline
\end{tabular}

${ }^{a} \operatorname{Rif}^{\mathrm{r}}, \mathrm{Tet}^{\mathrm{r}}, \mathrm{Str}^{\mathrm{r}}, \mathrm{Cmp}^{\mathrm{r}}, \mathrm{Spc}^{\mathrm{r}}, \mathrm{Amp}^{\mathrm{r}}$, and $\mathrm{Kan}^{\mathrm{r}}$ indicate resistant to rifampicin, tetracycline, streptomycin carbenicillin, spectinomycin, ampicillin, and kanamycin, respectively. 
plemented $\Delta x o p X$ by transforming it with a broad-host-range plasmid bearing the $x o p X$ locus from $X$. euvesicatoria $85-10$ (pDSK519[xopX $\left.\left.{ }_{2623}\right]\right)($ Table 1$) \cdot \mathrm{pDSK} 519\left(x o p X_{2623}\right)$ restored $\Delta x o p X$ to wild-type (WT) levels of $X$. euvesicatoria growth and disease symptoms in infected tomato 'VF36' leaves. To confirm the contribution of XopX protein expression to $X$. euvesicatoria virulence, we generated $\mathrm{XopX}$ antisera for use in monitoring XopX protein levels in $X$. euvesicatoria cultures. Plasmid-borne $x o p X$ restored XopX protein expression to $\Delta x o p X$, although at higher levels than that detected for the WT. These results support the requirement of XopX for full $X$. euvesicatoria virulence (Metz et al. 2005) and allowed us to use $X$. euvesicatoria 85-10 (referred to from now on as WT) and $\Delta x o p X$ for further study of XopX function.

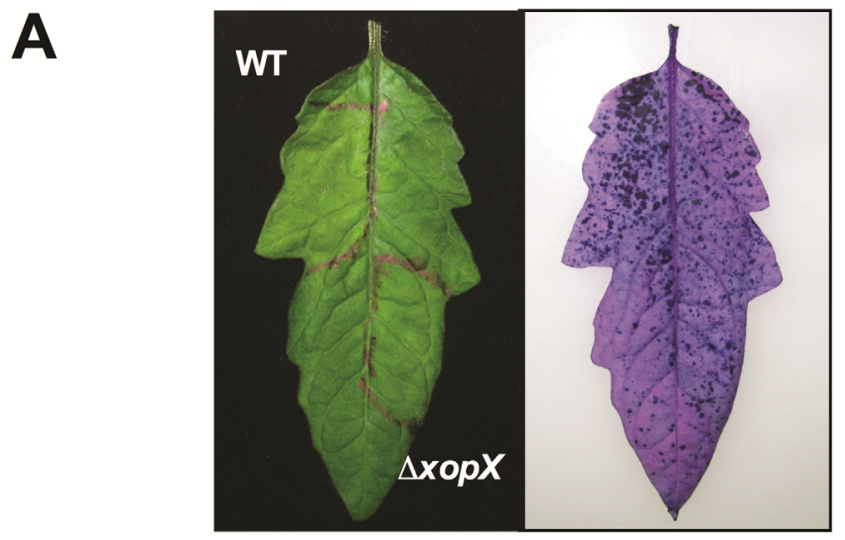

2 dpi

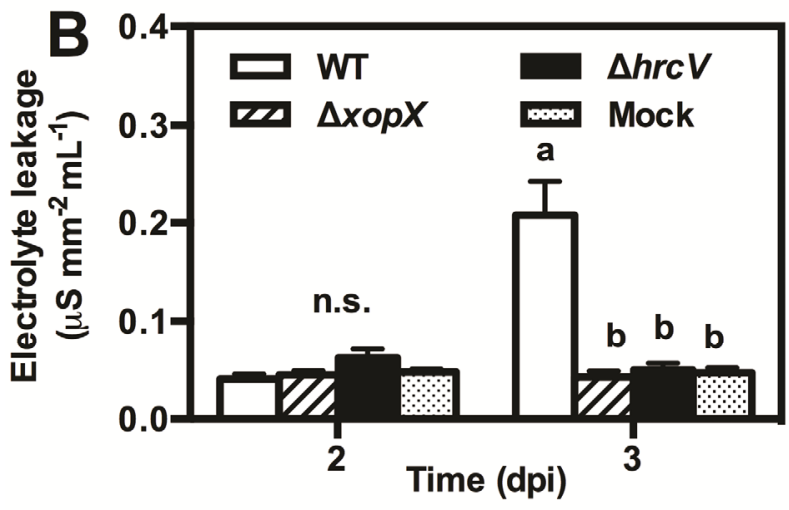

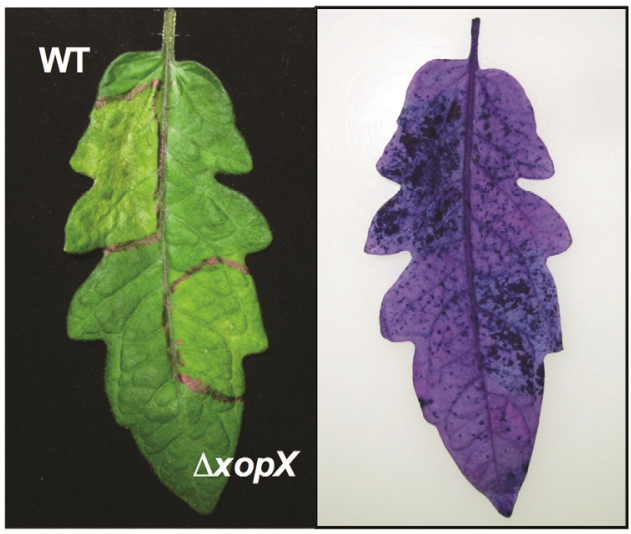

3 dpi
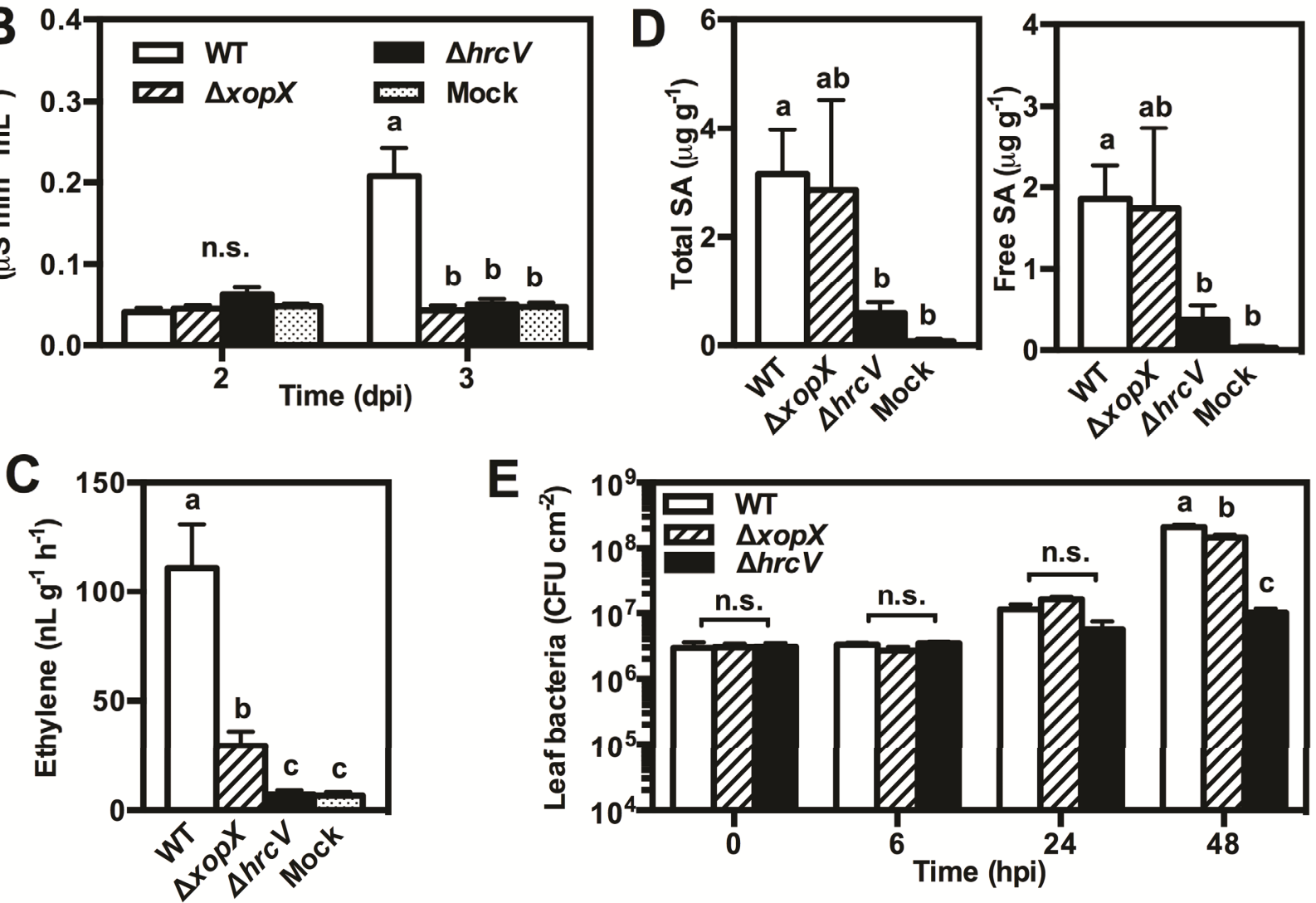

Fig. 1. XopX contribution to plant cell death (PCD) and phytohormone accumulation during Xanthomonas euvesicatoria infection of susceptible tomato. A, Tomato VF36 leaves were inoculated with the wild type (WT) and $\Delta x o p X$ at $2 \times 10^{8} \mathrm{CFU} \mathrm{ml}^{-1}$ in specific regions of the same leaflet or $\mathbf{B}$ to $\mathbf{D}$, whole leaflets were inoculated with WT, $\Delta x o p X$, or $\Delta h r c V$ at $2 \times 10^{8} \mathrm{CFU} \mathrm{ml}{ }^{-1}$ or $1 \mathrm{mM} \mathrm{MgCl}$ (mock). A, Leaflets were harvested 1,2 , or 3 days postinoculation (dpi) and photographed before (left insets) and after (right insets) staining with trypan blue to highlight regions of PCD. B, Four leaf disks from each treatment were harvested at 1,2 , or $3 \mathrm{dpi}$, washed, and floated on $5 \mathrm{ml}$ of distilled water for $4 \mathrm{~h}$ with gentle shaking prior to measuring the conductivity of bathing water. Values are mean conductivity of bathing water $\left(\mu \mathrm{S} \mathrm{mm} \mathrm{mm}^{-2}\right.$ leaf $\mathrm{ml}^{-1}$ bathing water) \pm standard deviation (SD) $(n=3$ plants). C, Inoculated whole leaflets were harvested $48 \mathrm{~h}$ postinoculation (hpi) and placed into separate sealed vials with minimal damage. Ethylene (ET) gas in headspace around the leaflet was quantified by gas chromatography over the course of $1 \mathrm{~h}$. Values are mean ET concentration $\left(\mathrm{nl} \mathrm{ET} \mathrm{g}^{-1}\right.$ leaf $\left.\mathrm{h}^{-1}\right) \pm \mathrm{SD}(n=4$ plants). D, Leaf disks from inoculated leaflets were harvested 48 hpi and total (left) and free (right) salicylic acid (SA) were quantified using the Acinetobacter sp. ADPWH_lux biosensor. Values are mean total or free SA ( $\mu \mathrm{g}$ SA $\mathrm{g}^{-1}$ leaf) $\pm \mathrm{SD}$ ( $n=4$ plants). E, Tomato VF36 leaves were inoculated with $X$. euvesicatoria WT, $\Delta x o p X$, or $\Delta h r c V$ at $2 \times 10^{8} \mathrm{CFU}^{-1}$. Leaf bacteria were enumerated for each treatment $0,6,24$, and 48 hpi. Values are mean leaf bacteria (CFU cm ${ }^{-1}$ leaf) \pm SD $(n=4)$. Different letters above bars indicate statistically significant differences as determined by two-way analysis of variance (ANOVA) and Tukey's honestly significant difference (HSD), $P<0.05$ (B and E) or one-way ANOVA and Tukey's HSD, $P<0.05(\mathrm{C}$ and $\mathrm{D})$; n.s. = no significant differences among treatments. 
XopX is required for $X$. euvesicatoria-induced ET and PCD in susceptible tomato.

Previous studies have shown that some Pseudomonas T3Es required for full pathogenicity also promote PCD (i.e., the functionally redundant T3E pairs AvrE1/HopM1 and AvrPto/ AvrPtoB), possibly as a consequence of their virulence function (Badel et al. 2006; Cohn and Martin 2005). Given that $\mathrm{XopX}$ is required for symptom development and tissue necrosis during $X$. euvesicatoria infection of tomato, we tested whether or not XopX is required for X. euvesicatoria-induced PCD in tomato by performing trypan blue staining of tomato leaves inoculated with $X$. euvesicatoria. High-titer $\left(2 \times 10^{8}\right.$ $\mathrm{CFU} \mathrm{m} \mathrm{m}^{-1}$ ) inoculation of $X$. euvesicatoria into susceptible tomato leaves results in PCD and tissue collapse 3 to 5 days postinoculation (dpi) (Fig. 1A). The extent of cell death can be visualized by the relative amount of trypan blue stain taken up by dead cells. As expected, tomato leaves inoculated with WT were heavily stained with trypan blue by 3 dpi (Fig. 1A). However, tomato leaves inoculated with $\Delta x o p X$ had lower levels of staining (Fig. 1A), suggesting that XopX is required for $X$. euvesicatoria-induced PCD in tomato.

To quantify XopX's contribution to X. euvesicatoria-induced PCD in tomato, we measured electrolyte leakage from leaves inoculated with $1 \mathrm{mM} \mathrm{MgCl}$ (mock) or WT, $\Delta x o p X$, or $\Delta h r c V$ (an X. euvesicatoria 85-10 mutant unable to secrete T3Es) at $2 \times$ $10^{8} \mathrm{CFU} \mathrm{ml}^{-1}$ (Rossier et al. 1999). At $3 \mathrm{dpi}$, electrolyte leakage from leaves inoculated with WT was significantly higher than the mock treatment (Fig. 1B). By contrast, electrolyte leakage from $\Delta h r c V$-inoculated leaves was similar to the mock treatment (Fig. 1B), indicating that the secretion of T3Es is required for $X$. euvesicatoria-induced PCD. Electrolyte leakage from $\Delta x o p X$-inoculated leaves was similar to electrolyte leakage from $\Delta h r c V$-inoculated leaves and the mock treatment (Fig. $1 \mathrm{~B})$, suggesting that T3S of XopX causes PCD or that XopX is required for $\mathrm{PCD}$ caused by another T3E.

During both $X$. euvesicatoria and $P$. syringae pv. tomato infection of susceptible tomato, PCD and the resulting symptom development is positively regulated, in part, by host factors, such as the phytohormones ET and SA (del Pozo et al. 2004; Lund et al. 1998; O’Donnell et al. 2001, 2003). In fact, specific $X$. euvesicatoria T3Es suppress ET and SA signaling to mitigate symptom development in susceptible plants and promote $X$. euvesicatoria growth (Kim et al. 2008, 2013; Ustun et al. 2013). Although ET and SA signaling are activated during ETI in resistant plants, less is known about how these phytohormones are activated by T3Es in susceptible plants (Bari and Jones 2009). Previously, the elicitation of PCD by AvrPto and AvrPtoB was linked to their promotion of ET biosynthesis (Cohn and Martin 2005). Because XopX is required for $X$. euvesicatoria-induced PCD (Fig. 1A and B), we next tested the role of XopX in promoting ET and SA production in susceptible tomato leaves. Consistent with previous reports (O'Donnell et al. 2001, 2003; Kim et al. 2013), inoculation of WT at $2 \times 10^{8} \mathrm{CFU} \mathrm{ml}{ }^{-1}$ significantly increased ET accumulation in tomato leaves compared with mock inoculation by 2 dpi (Fig. 1C). A low level of ET was detected in $\Delta h r c V$ - and mockinoculated leaves (Fig. 1C), demonstrating that X. euvesicatoriainduced ET requires the secretion of T3Es. The ET level in

\section{A}

\section{N. benthamiana}
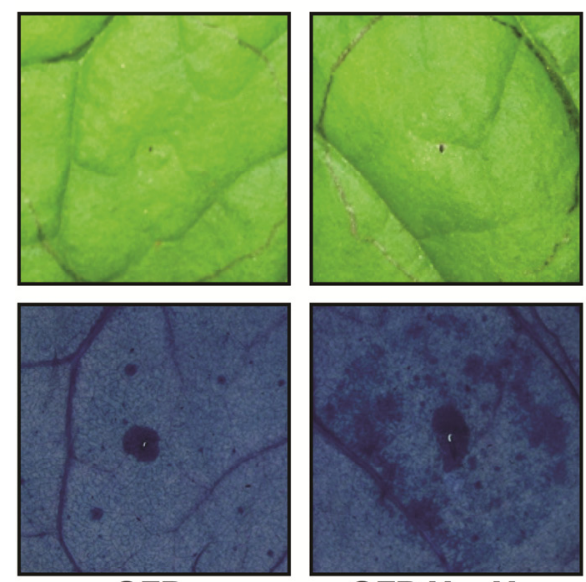

GFP
B

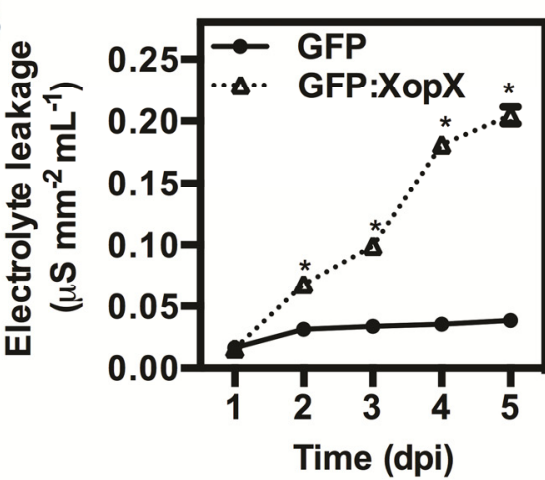

D
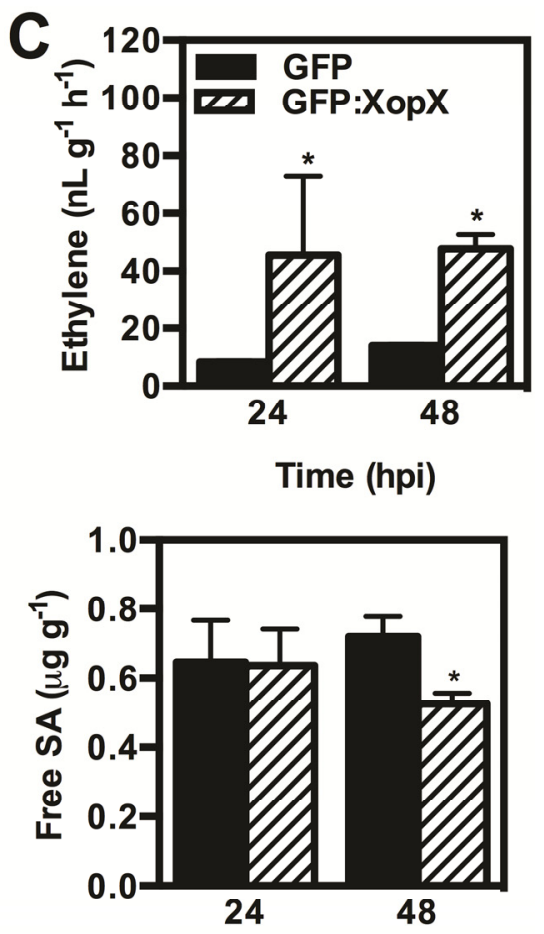

Time (hpi)

Fig. 2. Plant cell death (PCD) and phytohormone accumulation in Nicotiana benthamiana leaves after transient expression of green fluorescent protein (GFP):XopX. Agrobacterium tumefaciens strains bearing binary vectors for GFP or GFP:XopX expression were inoculated into N. benthamiana leaves at 4 $\times 10^{8} \mathrm{CFU} \mathrm{m}{ }^{-1}$. A, Leaves were harvested at 3 days postinoculation (dpi) and photographed before (top) and after (bottom) staining with trypan blue to indicate regions of PCD. B, Four leaf disks from each treatment were harvested $20 \mathrm{~h}$ postinoculation (hpi), washed, and floated on $5 \mathrm{ml}$ of distilled water. Conductivity of bathing water was measured at $24 \mathrm{hpi}$ and every subsequent $24 \mathrm{~h}$ for 5 days. Values are mean conductivity of bathing water ( $\mu \mathrm{S}$ mm ${ }^{-2}$ leaf $\mathrm{ml}^{-1}$ bathing water) \pm standard deviation (SD) ( $n=3$ plants). C, Inoculated regions were harvested at 24 and 48 hpi and placed into separate sealed vials with minimal damage. Ethylene (ET) gas in headspace around leaf was quantified by gas chromatography over the course of 1 h. Values are mean ET concentration (nl ET g ${ }^{-1}$ leaf $\left.\mathrm{h}^{-1}\right) \pm \mathrm{SD}(n=3$ plants). D, Leaf disks were harvested 24 and 48 hpi and total (left) and free (right) salicylic acid (SA) was quantified using the Acinetobacter sp. ADPWH_lux biosensor. Values are mean total or free SA ( $\mu \mathrm{g}$ SA g ${ }^{-1}$ leaf) \pm SD ( $n=3$ plants). B to D, Asterisks above bars indicate statistically significant differences as determined by two-way analysis of variance and Tukey's honestly significant difference, $P<0.05$. 
$\Delta x o p X$-inoculated leaves was $26 \%$ of that in WT-inoculated leaves on average, indicating that XopX alone accounts for the majority of the ET accumulation induced by WT (Fig. 1C). However, the ET level in $\Delta h r c V$-inoculated leaves was still significantly lower than that in $\Delta x o p X$-inoculated leaves (only $6 \%$ of WT), suggesting that other X. euvesicatoria T3Es contribute to ET accumulation, albeit to a lesser extent.

Total and free SA levels in WT-inoculated leaves were significantly higher than that in $\Delta h r c V$ - and mock-inoculated leaves (Fig. 1D), suggesting that SA accumulation during $X$. euvesicatoria infection is also primarily T3S dependent. This accumulation was not dependent on XopX because SA levels in $\Delta x o p X$-inoculated leaves were similar to those in WT-inoculated leaves (Fig. 1D).

Therefore, the results of our PCD and phytohormone analyses in $X$. euvesicatoria-inoculated tomato leaves indicate that the primary tomato phenotypes associated with the presence of XopX within the plant cell are the production of ET (Fig. 1D and E) and the activation of PCD (Fig. 1A and B). We also quantified $X$. euvesicatoria growth in tomato leaves to account for the contribution of bacterial load to PCD and ET production during these experiments. Prior to the onset of PCD and tissue collapse at $3 \mathrm{dpi}$, WT and $\Delta x o p X$ populations increased approximately 10 -fold and were present at similar titers at 0,6 , and $24 \mathrm{~h}$ postinoculation (hpi), although WT was significantly higher than $\Delta x o p X$ at $48 \mathrm{hpi}$ (Fig. 1E). By contrast, $\Delta h r c V$ grew less and was significantly lower than both WT and $\Delta x o p X$ at 48 hpi (Fig. 1E). Because $\Delta x o p X$ and $\Delta h r c V$ elicited similar PCD (Fig. 1B) and ET (Fig. 1C) phenotypes but had different growth patterns (Fig. 1E), bacterial titer alone does not explain the lack of PCD and ET elicited by the $\triangle x o p X$ strain. Therefore, these data suggest that the difference in PCD and ET production between WT- and $\Delta x o p X$-inoculated leaves was primarily due to the presence of XopX. To confirm this hypothesis, we next expressed XopX in planta to determine whether XopX alone is sufficient for elicitation of PCD and ET.

\section{Transient XopX expression promotes ET and PCD in $N$. benthamiana.}

The bacterial genetic approach for studying XopX described above may be complicated by the presence of other $X$. euvesicatoria T3Es as well as the growth defect of the $\Delta x o p X$ strain. Therefore, to study XopX function in isolation, we transiently transformed $N$. benthamiana leaf cells to express XopX with an N-terminal green fluorescent protein (GFP) tag (GFP:XopX) and then monitored PCD and ET production. We chose $N$. benthamiana as the host because Agrobacterium-mediated transient transformation of $N$. benthamiana is more efficient than tomato. Consistent with the requirement of XopX for X. euvesicatoria-induced PCD in tomato (Fig. 1), transient expression of XopX in $N$. benthamiana was previously reported to cause PCD either on its own or in conjunction with an unidentified, T3S-dependent factor (Metz et al. 2005; Salomon et al. 2011). In our experiments, transient expression of GFP:XopX alone caused weak PCD in N. benthamiana leaves (Fig. 2A). Macroscopic PCD was usually not visible before 3 to $4 \mathrm{dpi}$, although trypan blue staining and electrolyte leakage measurements of regions expressing GFP:XopX (Fig. 2A and B) provided evidence of detectable PCD beginning $48 \mathrm{hpi}$.

Next, we used this transient expression system to test whether the presence of XopX in the plant cell is sufficient to promote ET production. Transient expression of GFP:XopX but not GFP induced ET accumulation in $N$. benthamiana leaves (Fig. 2C) prior to the onset of XopX-induced PCD. Therefore, XopX is both required (X. euvesicatoria-inoculated tomato, Fig. 1D) and sufficient (transient expression in N. benthamiana) to elicit ET production prior to PCD. By contrast, total SA accumulation was similar in regions expressing GFP and GFP:XopX. Free SA accumulation was slightly less in regions expressing GFP:XopX than in those expressing GFP (Fig. 2D). This slight suppression of free SA accumulation might be a consequence of XopX-triggered ET production, because data from Arabidopsis thaliana suggests that ET signaling can antagonize SA signaling (Kunkel and Brooks 2002).

\section{XopX promotes PTI gene transcript accumulation but suppresses PTI-associated ROS.}

The finding that XopX promotes ET production and PCD is consistent with the requirement of XopX in promoting $X$. euvesicatoria symptom development but it does not explain how XopX contributes to $X$. euvesicatoria growth. Although AvrPto and AvrPtoB were shown to elicit ET and PCD during $P$. syringae pv. tomato infection of tomato (Cohn and Martin 2005), subsequent research has suggested that their primary role is suppression of plant immune signaling by plant cell receptor-kinases (Gimenez-Ibanez et al. 2009; Gohre et al. 2008; Xiang et al. 2008). Indeed, a primary function of phytopathogenic T3Es in promoting bacterial growth is the suppression of plant immune signaling at different nodes (Mukhtar et al. 2011). Because XopX is also required for full $X$. euvesicatoria growth in susceptible plants, we next sought to explicitly test whether XopX suppresses PTI signaling during X. euvesicatoria infection of susceptible tomato by monitoring the transcript levels of known PTI genes (i.e., SlPti5, SlWRKY28, SILRR22, and SIGRAS2) in response to X. euvesicatoria with or without XopX. Previously, transcripts of these genes were found to increase in response to flagellin and infection by T3S mutants of $P$. syringae pv. tomato and $X$. euvesicatoria, and were suppressed by the X. euvesicatoria T3E, XopN (Kim et al. 2009; Nguyen et al. 2010). We used quantitative polymerase chain reaction (qPCR) to quantify the transcript levels of these genes in tomato 'VF36' leaves inoculated with $1 \mathrm{mM}$ $\mathrm{MgCl}_{2}$ or a high titer $\left(2 \times 10^{8} \mathrm{CFU} \mathrm{m}{ }^{-1}\right)$ of WT, $\Delta x o p X$, or $\Delta h r c V$ at 6 and $12 \mathrm{hpi}$. As expected, $\Delta h r c V$ treatment induced transcript accumulation for all four PTI genes relative to the mock treatment, and this induction was suppressed by WT treatment (Fig. 3A). SIPti5 and SILRR22 were significantly lower in WT-inoculated leaves than in $\Delta h r c V$-inoculated leaves, while SlWRKY28 and SIGRAS2 were slightly-though not significantly-lower in WT than $\Delta h r c V$ (Fig. 3A). Surprisingly, PTI gene transcripts tended to be lower in $\Delta x o p X$-inoculated leaves than in WT-inoculated leaves (Fig. 3A). A significant difference was observed for SlLRR22 (Fig. 3A). Thus, XopX appears to weakly promote, rather than suppress, a plant defense response in tomato, at least at the level of transcript accumulation.

We next tested whether XopX is sufficient to suppress PTI elicited by $P$. syringae pv. tomato using transient expression of XopX in $P$. syringae pv. tomato-infected $N$. benthamiana leaves. We monitored XopX-dependent suppression of PTI prior to the onset of XopX-induced PCD in this system. Treatment of $N$. benthamiana leaves with T3S-deficient $P$. syringae pv. tomato $(\Delta h r c U)$ triggers transcript accumulation of the PTI genes NbAcre31 and NbPti5 (Nguyen et al. 2010). We treated $N$. benthamiana leaves transiently expressing GFP or GFP: XopX with a T3S-deficient $P$. syringae pv. tomato strain $(\Delta h r c U)$ at $2 \times 10^{8} \mathrm{CFU} \mathrm{ml}{ }^{-1}$ and quantified PTI gene transcript accumulation. $P$. syringae pv. tomato $\Delta h r c U$ treatment triggered accumulation of NbAcre 31 and NbPti5 transcripts compared with a mock treatment in leaf tissue expressing GFP although, for NbPti5, this increase was not statistically significant (Fig. 3B). Gene transcript levels were the same (NbAcre31) or higher (NbPti5) in the $P$. syringae pv. tomato $\Delta h r c U$-inoculated leaf tissue expressing GFP:XopX compared with that 
expressing GFP (Fig. 3B). However, GFP:XopX expression alone triggered accumulation of these transcripts, and $P$. syringae pv. tomato $\Delta h r c U$ treatment did not have a further effect on their accumulation (Fig. 3B). XopX induction of PTI gene expression in $N$. benthamiana is consistent with our results using X. euvesicatoria in tomato and further suggests that XopX itself promotes defense in planta.

Finally, we sought to test the effect of XopX on extracellular ROS production, a nontranscriptional PTI response. Application of flg22, a 22-amino-acid peptide derived from flagellin, to $N$. benthamiana leaf tissue elicits the rapid accumulation of extracellular ROS which, as in Arabidopsis thaliana, requires a plasma membrane-localized NAPDH oxidase, NbRbohD (Segonzac et al. 2011). We treated leaf disks transiently expressing GFP or GFP:XopX with $200 \mathrm{nM}$ flg22 and quantified the resulting ROS burst. By contrast to PTI transcript accumulation, GFP:XopX but not GFP alone was sufficient to prevent flg22-induced ROS burst (Fig. 3C). This confirms that XopX presence in the plant cell suppresses at least one PTI output. However, this suppression activity is contradictory to the activation of plant defense gene transcription by XopX.

XopX interferes with PCD induced by Pto-AvrPto, mitogen-activated protein kinase (MAPK) signaling, or Bax.

Although there is an overlap in the signaling components and outputs involved in PTI and ETI (Thomma et al. 2011; Tsuda and Katagiri 2010), the ability to suppress both PTI and ETI appears to be restricted to a subset of phytopathogenic T3Es (Feng et al. 2012; Guo et al. 2009). Such dual activity suggests that these T3Es either target a regulatory node common to both pathways or have multiple plant targets or suppression activities. Therefore, we assessed the versatility of XopX in suppressing plant immune responses by testing its ability to suppress ETI. In $N$. benthamiana, transient coexpression of the P. syringae pv. tomato T3E AvrPto and its cognate resistance
A

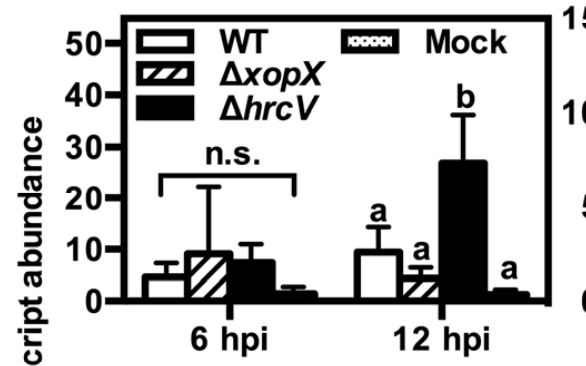

SILRR22

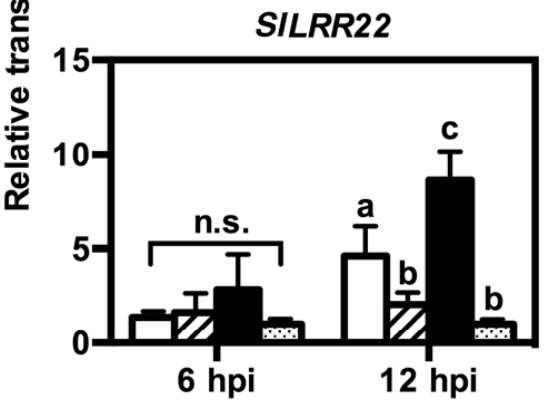

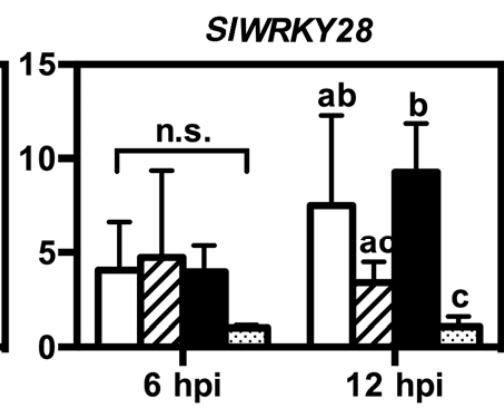

SIGRAS2

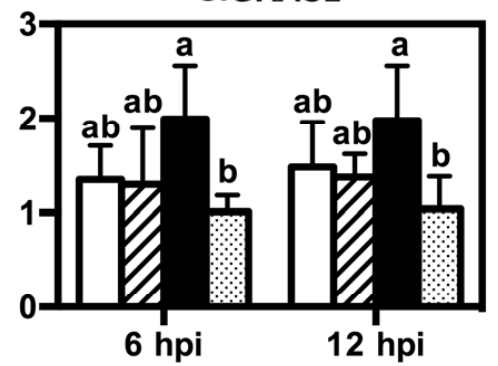

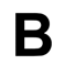

3

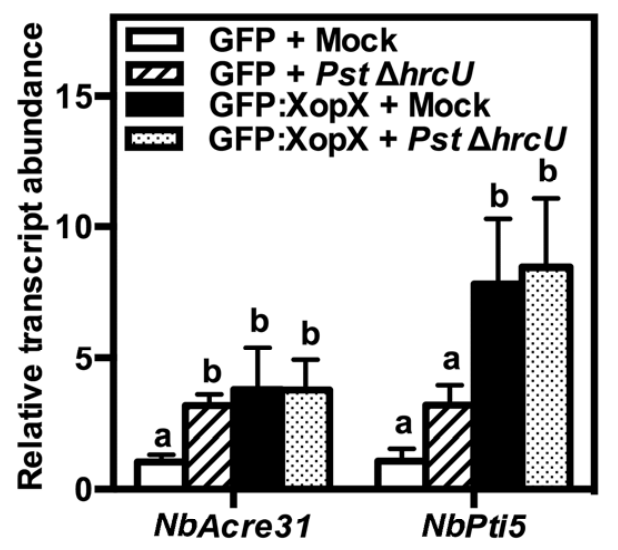

Time (hpi)

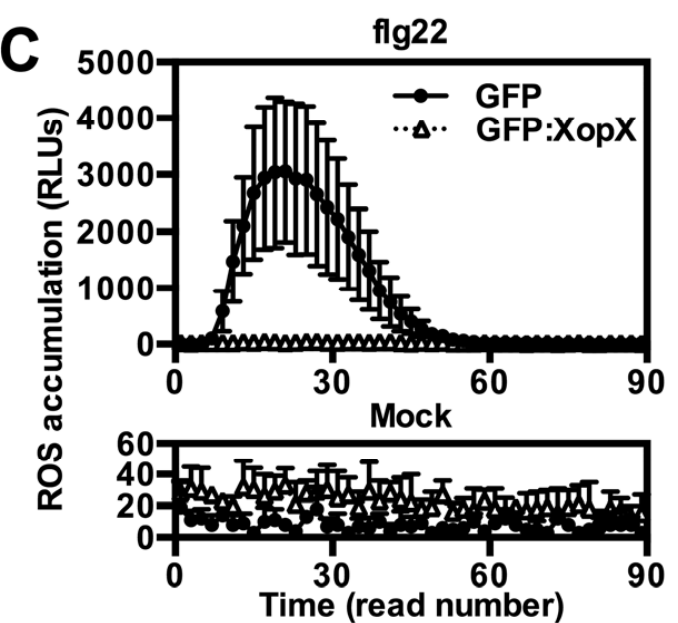

Fig. 3. Effect of XopX on pattern-triggered immunity (PTI) responses in tomato and Nicotiana benthamiana. A, Tomato VF36 leaves were inoculated with Xanthomonas euvesicatoria wild type (WT), $\triangle x o p X$, or $\Delta h r c V$ at $2 \times 10^{8} \mathrm{CFU} \mathrm{ml}^{-1}$ or $1 \mathrm{mM} \mathrm{MgCl}_{2}$ (mock). Samples were harvested 6 and $12 \mathrm{~h}$ postinoculation (hpi) for RNA extraction and cDNA synthesis. Transcript levels for known tomato PTI gene markers (i.e., SlPti5, SlWRKY28, SlLRR22, and SlGRAS2) were quantified by quantitative polymerase chain reaction (qPCR). Relative fold change in transcript abundance for each gene was calibrated to the average $\Delta$ cycle threshold $\left(\Delta \mathrm{C}_{\mathrm{T}}\right)$ values from the control treatment (mock) with SIACTIN as the internal control (Livak and Schmittgen 2001). Values are mean relative fold induction $\left(2^{-\Delta \Delta C T}\right) \pm$ standard deviation (SD) $(n=4$ plants). B, Agrobacterium tumefaciens strains bearing binary vectors for green fluorescent protein (GFP) or GFP:XopX expression were inoculated into $N$. benthamiana leaves at $4 \times 10^{8} \mathrm{CFU} \mathrm{ml}^{-1}$. At $24 \mathrm{hpi}$, intact leaves were inoculated with $1 \mathrm{mM} \mathrm{MgCl}_{2}$ (mock) or $2 \times 10^{8} \mathrm{CFU} \mathrm{ml} l^{-1}$ of Pseudomonas syringae pv. tomato $\Delta h r c U$. Leaf tissue was harvested $6 \mathrm{~h}$ after $\Delta h r c U$ treatment for RNA extraction and cDNA synthesis. Transcript levels for known PTI gene markers (i.e., NbAcre31 and NbPti5) were quantified by qPCR using the comparative $\mathrm{C}_{\mathrm{T}}$ method. Relative fold change in transcript abundance for each gene was calibrated to the average $\Delta \mathrm{C}_{\mathrm{T}}$ values from the control treatment (empty vector + mock), with $N b P P 2 A$ as the internal control. Values are mean relative fold induction $\left(2^{-\Delta \Delta C T}\right) \pm \operatorname{SD}(n=4$ plants $)$. C, GFP or GFP:XopX were expressed in $N$. benthamiana leaves as in B. At $24 \mathrm{hpi}$, three leaf disks were harvested and floated on distilled water in individual wells of a 96-well plate overnight under continuous light. Water was removed and replaced with horseradish peroxidase solution with $200 \mathrm{nM}$ flg22 (flg22, top) or without flg22 (mock, bottom). $\mathrm{H}_{2} \mathrm{O}_{2}$ production was quantified for 90 min after flg22 treatment using a plate reader luminometer. Each plate read lasted approximately $50 \mathrm{~s}$. Values for each read are mean relative light units (RLU) produced $\pm \mathrm{SD}(n=4$ plants). Different letters above bars indicate statistically significant differences as determined by two-way analysis of variance (ANOVA) and Tukey's honestly significant difference (HSD), $P<0.05$ (A) or one-way ANOVA and Tukey's HSD, $P<0.05$ (B); n.s. $=$ no significant differences among treatments. 
(R) protein, Pto, initiates ETI signaling that culminates in PCD (Oh and Martin 2011a). We coexpressed Pto-AvrPto in N. benthamiana with either GFP or GFP:XopX and monitored PCD. Surprisingly, despite the fact that XopX induces weak PCD (Fig. 2A and B), GFP:XopX delayed PCD activated by PtoAvrPto (Fig. 4, left).

We next sought to exploit knowledge of the Pto-AvrPto ETI signaling pathway to determine the signaling node at which XopX may be acting (Oh and Martin 2011a). In N. benthamiana $\mathrm{NbMAPKKK} \alpha$, its downstream substrate NbMKK2, and MAPK NbSIPK and NbWIPK are required for PCD activated by Pto recognition of AvrPto (Oh and Martin 2011a). Additionally, transient expression of SIMAPKKK $\alpha$ or the constitutively active version of SIMKK2 (SIMKK2 ${ }^{\mathrm{DD}}$ ) both activate PCD (del Pozo et al. 2004; Oh and Martin 2011b), as does transient expression of a tomato MAPK, SIMPK1 (Fig. 4), which acts downstream in this pathway (Pedley and Martin 2004). To determine the effect of XopX expression on MAPK signaling in $N$. benthamiana, we coexpressed estradiol-inducible constructs of the tomato orthologs of each of the MAPK components with either GFP or GFP:XopX. In all cases, GFP:XopX delayed PCD caused by induction of the MAPK components (Fig. 4, middle).

Previously, the ability of Pseudomonas T3Es (including AvrPtoB) to suppress ETI was linked to general PCD suppression activity, including PCD elicited by transgenic expression of the mammalian apoptotic protein, Bax (Abramovitch et al. 2003; Jamir et al. 2004). To test the ability of XopX to suppress or antagonize PCD generally, we coexpressed the mammalian apoptotic protein Bax with either GFP or GFP:XopX. Again, GFP:XopX coexpression with Bax delayed Bax-induced PCD (Fig. 4, right).
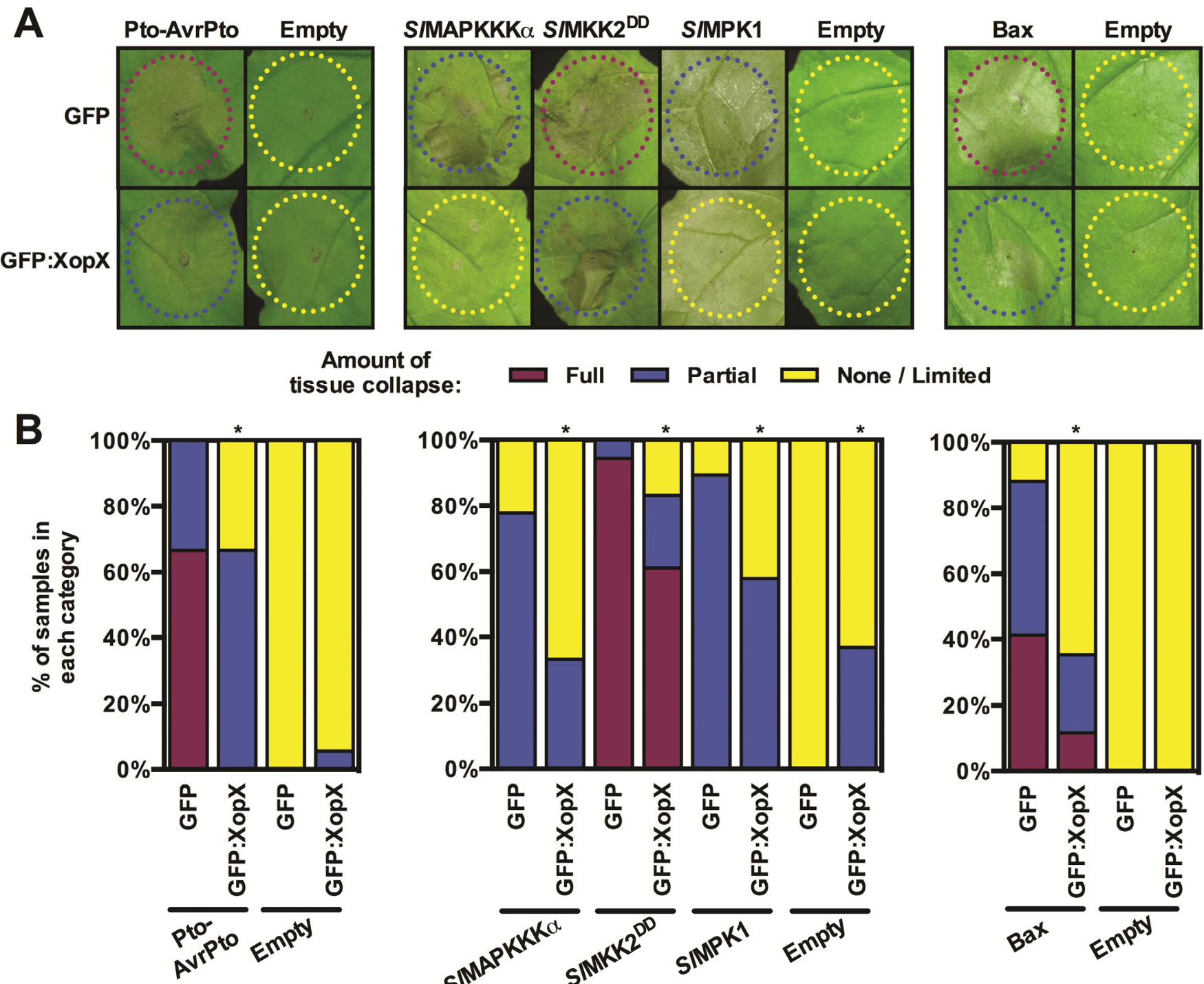

Amount of ssue collapse:

$\square$ Full $\square$ Partial

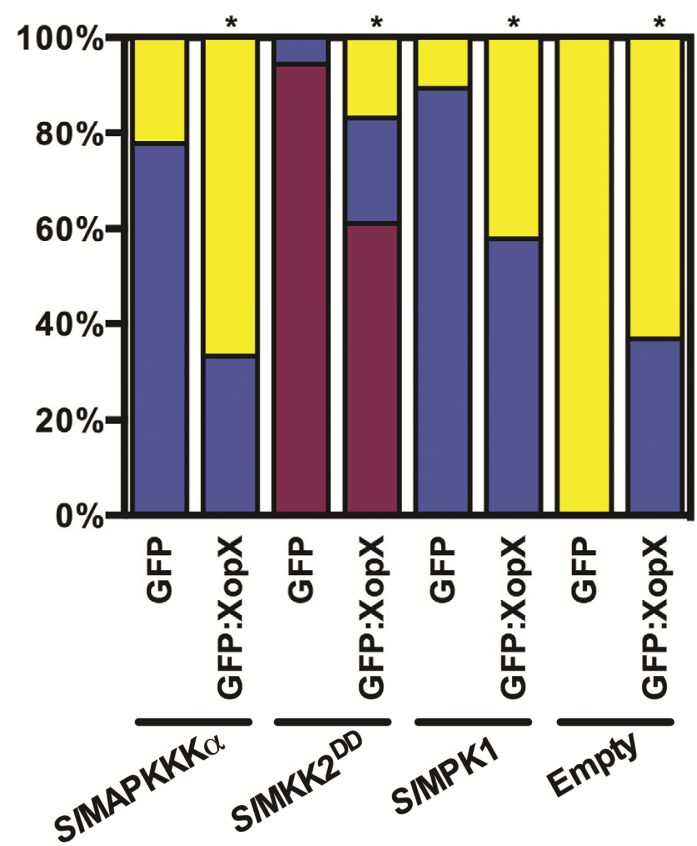

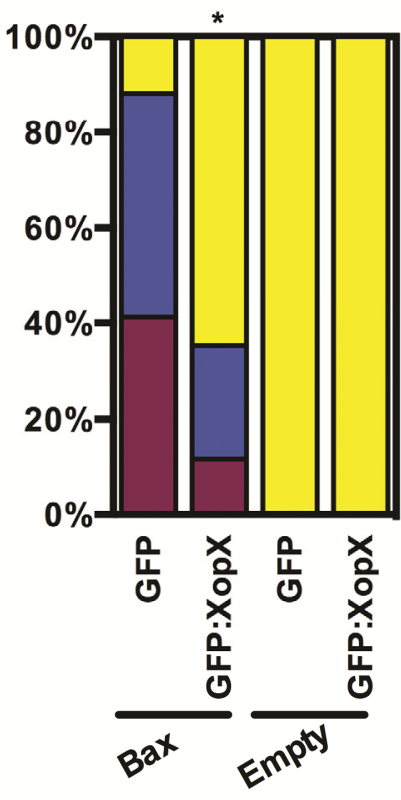

Fig. 4. Transient coexpression of green fluorescent protein (GFP):XopX and plant cell death (PCD) elicitors in Nicotiana benthamiana. Agrobacterium tumefaciens strains bearing binary vectors for GFP or GFP:XopX expression were co-inoculated into N. benthamiana leaves with strains bearing binary vectors for expression of PCD elicitors: Pto-AvrPto, mitogen-activated protein kinase (MAPK) signaling components, or Bax. A, Representative images of co-inoculations 3 days postinoculation (dpi) (Pto-AvrPto and Bax) or 5 dpi (MAPK components; 4 days after estradiol treatment). Circle indicates region of inoculation and color of circle indicates amount of tissue collapse (magenta = full, blue = partial, yellow = none or limited). B, Summary of tissue collapse scores for treatments shown in A. Bars indicate percentage of replicates $(n=18)$ in each category of tissue collapse using the same color scale as in A. Asterisks over bars indicate statistically significant difference in distribution of replicates among tissue collapse categories between GFP and GFP:XopX co-inoculations with each PCD elicitor as determined by Wilcoxon signed-rank test, $P<0.05$. Final A. tumefaciens concentrations in Pto-AvrPto co-inoculations were $2 \times$ $10^{8} \mathrm{CFU} \mathrm{ml}{ }^{-1}$ for all strains; in MAPK, component co-inoculations were $2 \times 10^{8} \mathrm{CFU} \mathrm{ml}^{-1}$ (GFP, GFP:XopX, SIMPK1, and empty) or $1 \times 10^{8} \mathrm{CFU} \mathrm{ml}^{-1}$ (SIMAPKKKa and SIMKK2 ${ }^{\mathrm{DD}}$ ); and, in Bax, co-inoculations were $4 \times 10^{8} \mathrm{CFU} \mathrm{ml}^{-1}$ for all strains. MAPK component constructs were driven by estradiolinducible promoters and estradiol was applied by spraying $24 \mathrm{~h}$ postinoculation. All other constructs were driven by the $35 S$ promoter. 
Activation of the NtMEK2 (the tobacco ortholog of SIMKK2) elicits ROS accumulation upstream of PCD, an effect also linked to Bax-elicited PCD (Kawai-Yamada et al. 2004; Liu et al. 2007). Therefore, we next monitored PCD-associated ROS accumulation by cytological staining of $\mathrm{H}_{2} \mathrm{O}_{2}$ with 3,3'-diaminobenzidine (DAB). Indeed, GFP:XopX coexpression with $\mathrm{NtMEK} 2^{\mathrm{DD}}$ in $N$. benthamiana resulted in reduced DAB staining compared with coexpression with GFP (Fig. 5A), suggesting that XopX acts upstream of ROS accumulation to suppress PCD.

We also analyzed whether XopX could suppress PCD by affecting the stability or abundance of PCD elicitors. Immunoblot analysis of hemagglutinin (HA)-tagged MAPK compo- nents resulted in detectable protein levels in both GFP- and GFP:XopX-expressing regions (Fig. 5B). Interestingly, all MAPK component protein levels were consistently lower in leaf tissue expressing GFP:XopX than in leaf tissue expressing GFP, correlating with reduced PCD in those regions (Fig. 5B). Notably, reduction of MAPK component protein levels occurred prior to tissue collapse and had a negative correlation with the level of PCD (i.e., XopX reduced protein accumulation and PCD), suggesting that this effect was not due to PCD per se. Furthermore, XopX did not affect total protein levels, as determined by Ponceau staining of immunoblots and similar levels of nonspecific bands in immunoblots for both GFP and GFP:XopX samples (Fig. 5B). These data suggest that XopX
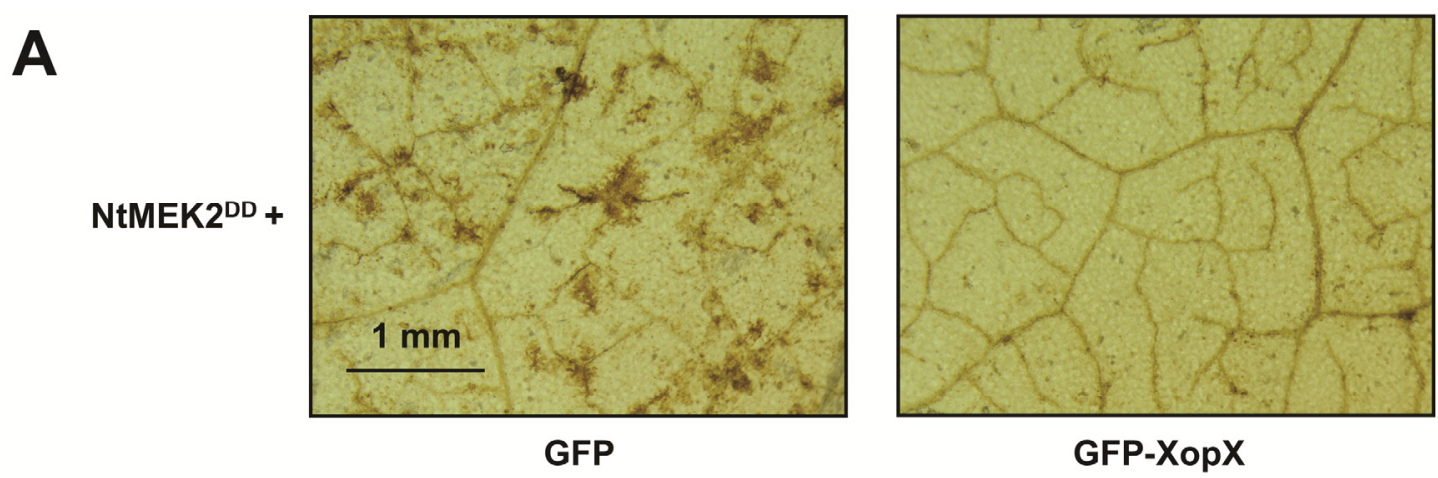

B

\section{SIMAPKKKa-HA}
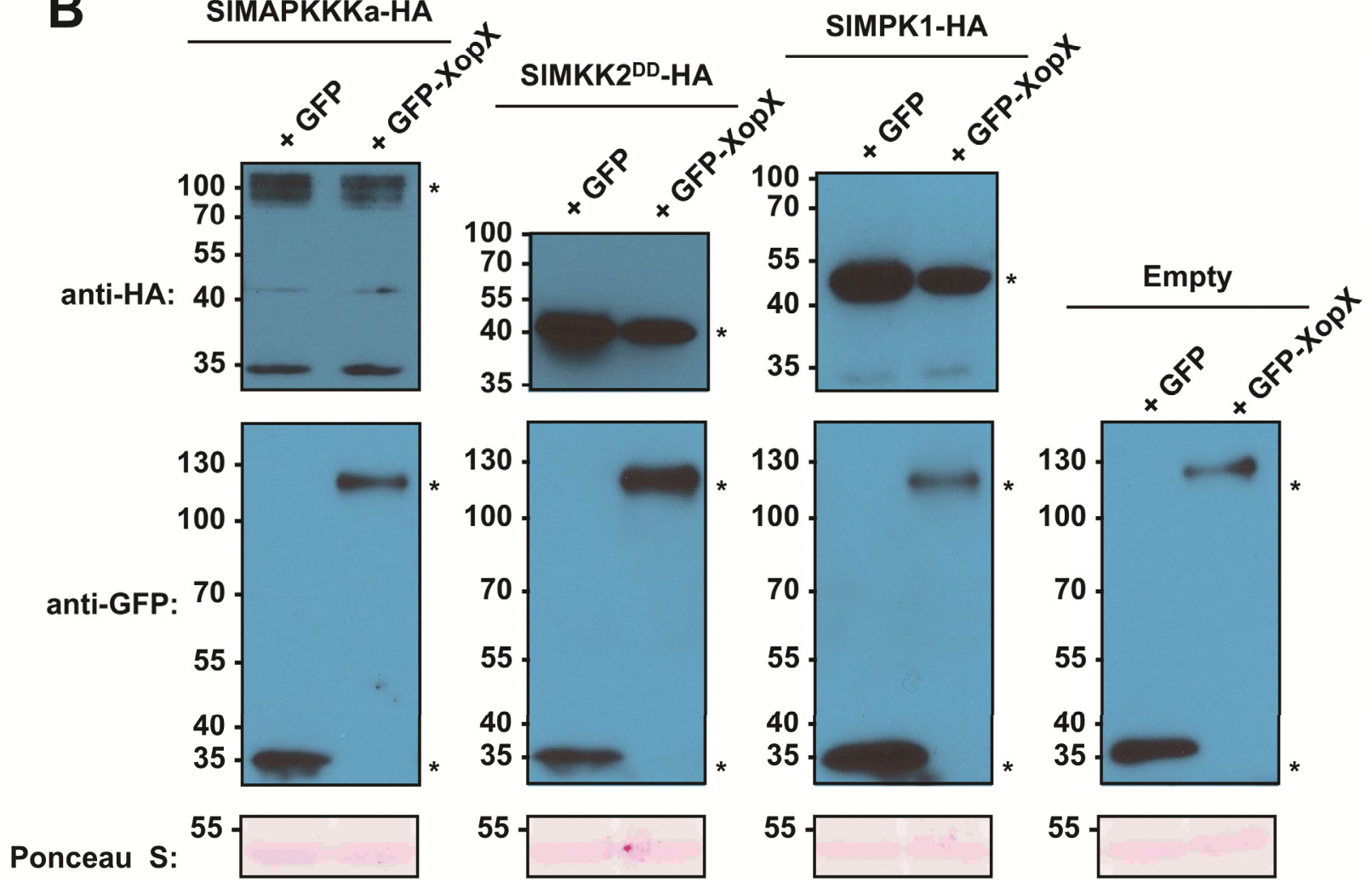

$55-$

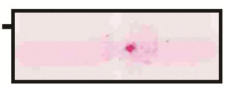

55

Fig. 5. Reactive oxygen species (ROS) accumulation and protein levels during green fluorescent protein (GFP):XopX coexpression with mitogen-activated protein kinase (MAPK) signaling components in Nicotiana benthamiana. A, Agrobacterium tumefaciens strains bearing GFP and GFP:XopX constructs were mixed to a final concentration of $2 \times 10^{8} \mathrm{CFU} \mathrm{ml}^{-1}$ with A. tumefaciens GV2260 pER8 $\left(N t M E K 2^{D D}\right)$. Estradiol was applied by spraying $24 \mathrm{~h}$ after infiltration. At $10 \mathrm{~h}$ after estradiol application, prior to the onset of macroscopic tissue collapse, infiltrated leaf tissue was vacuum infiltrated with $3,3^{\prime}$-diaminobenzidine solution. Leaf tissue was destained overnight in ethanol and imaged under a dissecting microscope. ROS accumulation is indicated by dark brown staining. B, A. tumefaciens strains bearing binary vectors for GFP or GFP:XopX expression were co-inoculated into $N$. benthamiana leaves with strains bearing binary vectors for expression of MAPK signaling components. Final A. tumefaciens concentrations were $2 \times 10^{8} \mathrm{CFU} \mathrm{ml}{ }^{-1}$ (GFP, GFP:XopX, SIMPK1, and empty) or $1 \times 10^{8} \mathrm{CFU}$ $\mathrm{ml}^{-1}$ (SIMAPKKKa and SIMKK2 ${ }^{\mathrm{DD}}$ ). MAPK component constructs were driven by estradiol-inducible promoters and estradiol was applied by spraying $24 \mathrm{~h}$ postinoculation. Leaf tissue was harvested $10 \mathrm{~h}$ after estradiol treatment for protein extraction. Protein from leaf extracts was separated by sodium dodecyl sulfate polyacrylamide gel electrophoresis and subjected to immunoblotting with anti-hemagglutinin (HA) or anti-GFP primary antibodies followed by horseradishperoxidase-conjugated secondary antibodies. Asterisks at right of blots indicate protein band corresponding to the labeled protein in each lane. 
alters the steady state levels of immune-related or highly expressed proteins specifically.

XopX does not contribute to ETI suppression in resistant tomato.

Because XopX interfered with the activity of a broad array of PCD elicitors in $N$. benthamiana, we hypothesized that XopX might interfere with ETI elicited by X. euvesicatoria in resistant tomato. Therefore, we tested whether resistant tomato exhibited increased ETI in response to $X$. euvesicatoria lacking xopX. The tomato 'Hawaii 7998' is resistant to WT and this resistance is triggered by the T3E AvrRxv (Whalen et al. 1993). We generated unmarked deletions of $a v r R x v$ in WT and $\Delta x o p X$ ( $\Delta a v r R x v$ and $\Delta x o p X \Delta a v r R x v$, respectively). Then, we monitored growth of these $X$. euvesicatoria strains in 'Hawaii 7998' and the susceptible tomato 'Hawaii 7981'. $\Delta x o p X$ growth was slightly reduced compared with WT in 'Hawaii 7998' leaves at 3 dpi but this defect was transient and not significant (Fig. 6A). By contrast, $\Delta x o p X$ growth was significantly lower than WT in Hawaii 7981 leaves (Fig. 6A). $\Delta a v r R x v$ growth was higher than WT in 'Hawaii 7998' but lower in Hawaii 7981 (Fig. 6A), suggesting a virulence role for AvrRxv that has not been previously reported (Bonshtien et al. 2005; Whalen et al. 1993). $\Delta x o p X \Delta a v r R x v$ growth was significantly lower than $\Delta a v r R x v$ in both 'Hawaii 7998' and '7981', further demon- strating that XopX virulence activity is independent of AvrRxv in both genetic backgrounds (Fig. 6A).

When inoculated into 'Hawaii 7998' leaves at high titer, $X$. euvesicatoria triggers rapid $\mathrm{PCD}$, which is characteristic of ETI (Whalen et al. 1993). We inoculated WT, $\Delta x o p X$, or $\Delta h r c V$ into 'Hawaii 7998' leaves at $2 \times 10^{8} \mathrm{CFU} \mathrm{ml}^{-1}$ and quantified electrolyte leakage from the leaves (Fig. 6B). Leaves inoculated with WT or $\Delta x o p X$ had similar levels of electrolyte leakage, which were significantly higher than $\Delta h r c V$ (Fig. 6B). This suggests that XopX is not able to suppress AvrRxv-elicited ETI in tomato. To confirm that the lack of ETI suppression by XopX was not specific to AvrRxv ETI, we repeated this experiment in transgenic tomato 'VF36' expressing the pepper resistance $(R)$ gene $B s 2$, which recognizes $a v r B s 2$ from WT (Tai et al. 1999). As in 'Hawaii 7998', WT elicited high levels of electrolyte leakage (significantly higher than $\Delta h r c V$ ) when inoculated at high titer into tomato 'VF36' Bs2 leaves (Fig. $6 \mathrm{~B})$. Electrolyte leakage from $\Delta x o p X$-inoculated leaves was similar to that from WT-inoculated leaves at $24 \mathrm{hpi}$ and slightly lower at $48 \mathrm{hpi}$ (Fig. 6B), indicating that XopX does not suppress AvrBs2 ETI and may, in fact, contribute to PCD associated with AvrBs2 ETI. These data suggest that, although transient expression of XopX in $N$. benthamiana interferes with PCD, X. euvesicatoria-delivered XopX is not a general suppressor of ETI in tomato.
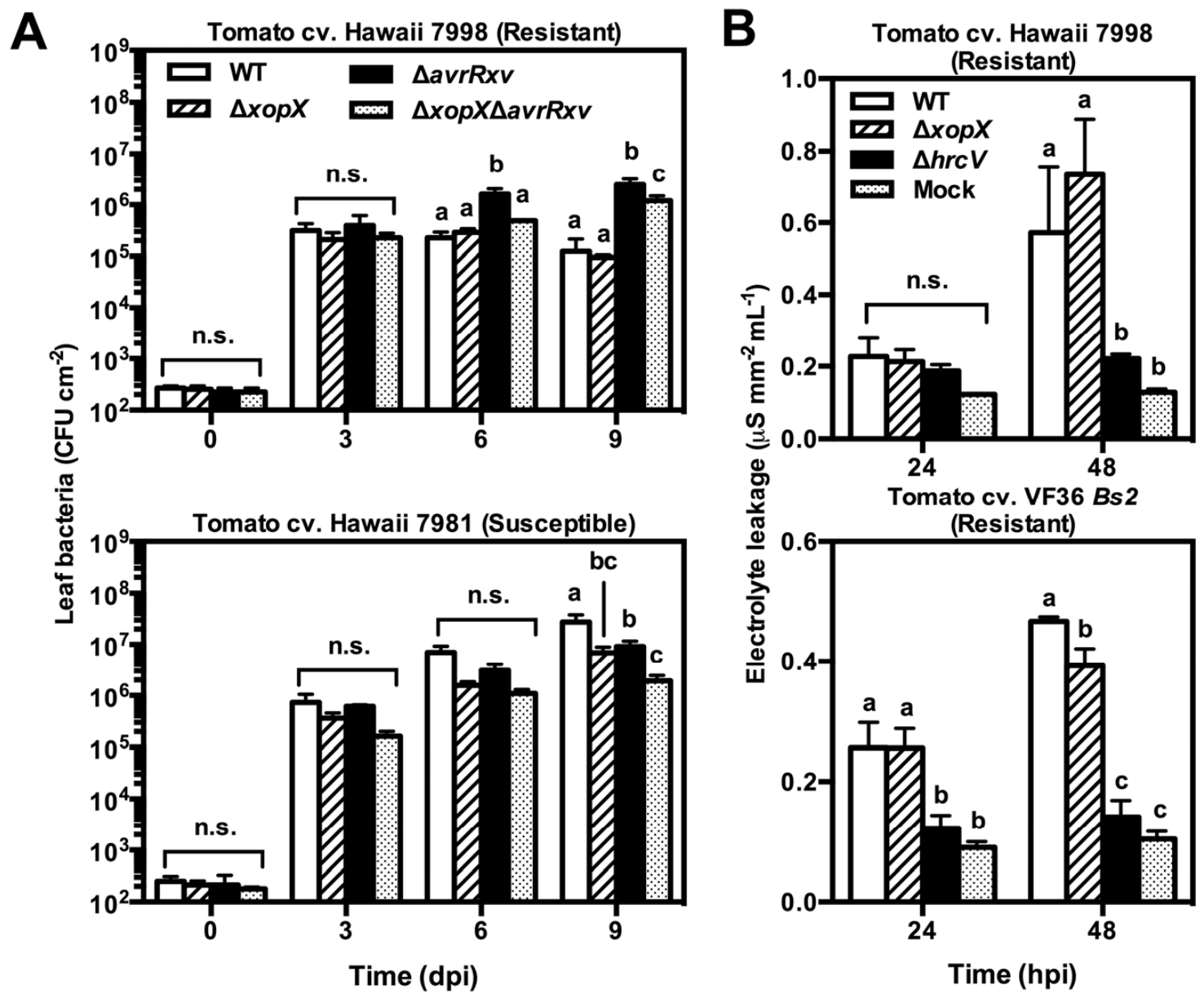

Fig. 6. Analysis of XopX effect on AvrRxv- and AvrBs2-dependent effector-triggered immunity (ETI) responses in tomato. A, Hawaii 7998 (resistant; top) or Hawaii 7981 (susceptible; bottom) tomato leaves were inoculated with Xanthomonas euvesicatoria wild type (WT), $\Delta x o p X$, $\Delta a v r R x v$, or $\Delta x o p X \Delta a v r R x v$ at $2 \times 10^{4} \mathrm{CFU} \mathrm{ml}{ }^{-1}$. Leaf bacteria were enumerated for each treatment $0,3,6$, and 9 days postinoculation (dpi). Values are mean leaf bacteria (CFU $\mathrm{cm}^{-1}$ leaf) \pm standard deviation (SD) $(n=3)$. B, Hawaii 7998 (top) or VF36 Bs2 (bottom) tomato leaves were inoculated with X. euvesicatoria WT, $\Delta x o p X$, or $\Delta h r c V$ at $2 \times 10^{8} \mathrm{CFU} \mathrm{ml}^{-1}$. Four leaf disks were harvested per sample at 24 and $48 \mathrm{~h}$ postinoculation (hpi), rinsed, and floated on $3 \mathrm{ml}$ of distilled water for $2 \mathrm{~h}$ with gentle shaking, and the conductivity of the bathing water was measured. Values are mean percent electrolyte leakage $\left(\mu \mathrm{S} \mathrm{mm}^{-2}\right.$ leaf $\mathrm{ml}^{-1}$ bathing water) $\pm \mathrm{SD}$ ( $n=3$ plants). Different letters above bars indicate statistically significant differences within each time point as determined by two-way analysis of variance and Tukey's honestly significant difference, $P<0.05$. 


\section{DISCUSSION}

We have identified a role for the Xanthomonas core T3E XopX in modulating plant immune signaling, including suppression of flagellin-induced ROS production and interference with rapid PCD elicited by Pto detection of AvrPto, activation of MAPK signaling, and the general cell death elicitor, Bax. However, we also found that XopX itself promotes plant defense gene transcription, ET production, and PCD during $X$. euvesicatoria infection of tomato and when transiently expressed in $N$. benthamiana. This complex combination of suppression and activation of immunity-related plant responses raises intriguing parallels with well-studied $P$. syringae pv. tomato T3Es, especially the core T3Es AvrE1 and HopM1 (Badel et al. 2006) and potent PTI suppressors AvrPto and AvrPtoB (Cohn and Martin 2005). Therefore, our results provide a useful starting point for contextualizing XopX function.

The plant immune system features multiple nodes that positively regulate immune signaling but negatively regulate each other; thus, perturbation of one node by a T3E may lead to hyperactivation of another (Sato et al. 2010). As recently noted (Kadota et al. 2014), null mutations in certain A. thaliana PTI signaling components display overactive immune responses, including increased PTI gene expression (He et al. 2007; Kadota et al. 2014; Kemmerling et al. 2007; Nishimura et al. 2003; Petersen et al. 2000; Zhang et al. 2010), leading to the hypothesis that severe perturbation of specific PTI signaling components is detected by the plant (Segonzac and Zipfel 2011).

Suppression of flg22-elicited ROS by XopX suggests that it interferes with plant immune signaling at an early stage. However, XopX promotes-rather than suppresses-PTI-elicited gene expression, indicating that it does not suppress PTI signaling to all downstream outputs. It is known that flg22-elicited PTI gene expression is independent of NbRbohD-mediated ROS production in N. benthamiana (Segonzac et al. 2011). Thus, our data is consistent with a model whereby XopX functions to target a specific node of plant immunity (i.e., NbRbohD-produced ROS). This targeting would not result in the suppression of PTI gene expression. Rather, perturbation of the node targeted by XopX would result in increased PTI gene transcription.

The idea that T3E perturbation of plant immunity itself leads to a plant defense response was put forward as a model to explain why the functionally redundant $P$. syringae pv. tomato T3Es AvrE1 and HopM1 suppress immunity but also cause $R$-gene-independent PCD across a range of plant species (Badel et al. 2006). In this default to death and defense model (Lindeberg et al. 2012), AvrE1 and HopM1 suppress plant immunity by interfering with a critical plant cell process: vesicle trafficking (Ham et al. 2009; Nomura et al. 2006). The plant cell responds to this perturbation of a critical cell process by initiating, in this case, a PCD response. The fact that AvrE1 and HopM1 elicit PCD in many plants suggests that this process is not mediated by $\mathrm{R}$ protein detection of a T3E but, instead, is a general response to T3E virulence activity (Badel et al. 2006; Lindeberg et al. 2012). XopX activation of PTI gene transcription, ET production, and PCD is consistent with this model. Notably, XopX is also cytotoxic in yeast (Salomon et al. 2011), which suggests that - although the cellular pathways leading to yeast cell death and PCD may differ-XopX may indeed target a basic cell process common among eukaryotes.

Whether it is suppressed by the pathogen or just ineffective in halting pathogen growth in susceptible plants, the default to death and defense model implies that the PCD that underlies symptom development may, in fact, be a plant defense response to T3Es. Consistent with plant regulation of PCD in susceptible interactions (i.e., through the phytohormones ET and SA), SIMAPKKK $\alpha$ (a positive regulator of ETI) is also required for
PCD during $P$. syringae pv. tomato infection of tomato (del Pozo et al. 2004). Previously, P. syringae pv. tomato T3Es AvrPto and AvrPtoB were shown to promote ET biosynthesis and subsequent PCD during $P$. syringae pv. tomato infection of tomato (Cohn and Martin 2005), although the direct mechanism by which these T3Es contribute to bacterial virulence appears to be through the inactivation of plant receptor-like kinases (Gimenez-Ibanez et al. 2009; Gohre et al. 2008; Xiang et al. 2008). Elicitation of defense-associated phytohormone signaling and PCD may then be a side effect of AvrPto/ AvrPtoB virulence activity-perhaps another example of the plant default to death and defense response-which hemibiotrophic pathogens must control in order to achieve maximum virulence. Indeed, X. euvesicatoria T3Es XopD and XopJ suppress ET- or SA-dependent symptom development during late stages of infection to increase bacterial pathogenesis (Kim et al. 2008, 2013; Ustun et al. 2013).

We cannot rule out the possibility that XopX-elicited PCD is due to weak detection by an R protein, although this seems unlikely given the correlation between $\mathrm{PCD}$ and bacterial virulence. XopX homologs are found in almost every sequenced Xanthomonas strain, and variation among XopX homologs at the amino acid sequence level correlates with Xanthomonas phylogeny. This suggests that XopX is an ancient Xanthomonas T3E and that it has evolved along with host-specific traits that distinguish Xanthomonas strains. It is not clear why XopX from $X$. euvesicatoria confers PCD-eliciting activity on $N$. benthamiana leaves in response to $X$. campestris pv. campestris (Metz et al. 2005), the genome of which encodes two XopX homologs. Future comparative studies of XopX homologs will help to distinguish whether variation in XopX is due to evolved virulence function or escape from host detection.

Because transient expression of XopX itself elicits PCD, we were surprised to find that XopX interfered with ETI and PCD elicited by Pto-AvrPto, MAPK signaling components, and Bax. Antagonism between PCD-eliciting T3Es has been previously described. For example, AvrRpt2-elicited ETI was shown to interfere with AvrRpm1-elicited ETI in A. thaliana (Reuber and Ausubel 1996; Ritter and Dangl 1996). This genetic relationship was later explained by the fact that prior AvrRpt 2 proteolysis of guardee protein RIN4 prevents phosphorylation of RIN4 by AvrRpm1 (Axtell and Staskawicz 2003; Kim et al. 2005; Mackey et al. 2002, 2003). XopX antagonism of a wide range of PCD elicitors is consistent with XopX targeting of a basic cell process required by the PCD pathways tested here. However, our results suggest that XopX is not a general suppressor of known ETI pathways when delivered by $X$. euvesicatoria in tomato (Fig. 6). These findings suggest that suppression of plant immunity by transient expression of T3Es should be interpreted with caution, because results may be affected by different levels of protein expression, biological differences between plant species (i.e., N. benthamiana and tomato), or the relative strength of different immune signaling pathways.

In conclusion, the study of highly conserved, core T3Es sheds light on the principal virulence strategies used by plant pathogens. Our results add XopX to the class of T3Es (along with AvrE1 and HopM1) that activate the plant default to death and defense response. Further elucidating the function of XopX and other core T3Es in this emerging T3E class will be important for uncovering the mechanisms that regulate both plant defense and symptom development during plant-microbe interactions.

\section{MATERIALS AND METHODS}

\section{Bacterial culture and transformation.}

Detailed descriptions of all bacterial strains and plasmids used are provided in Table 1. Escherichia coli strains were cul- 
tured with lysogeny broth (LB) $(\mathrm{pH} \mathrm{7.0,1 \%} \mathrm{tryptone,} 0.5 \%$ yeast extract, and $171 \mathrm{mM} \mathrm{NaCl}$ ) at $37^{\circ} \mathrm{C}, X$. euvesicatoria $85-$ 10 (and derivative strains) with nutrient yeast glycerol (NYG) (pH 7.0, 0.5\% peptone, $0.3 \%$ yeast extract, and $2 \%$ glycerol,) (Turner et al. 1984), or hrp-inducing medium (XVM2) $(\mathrm{pH}$ 6.7, $20 \mathrm{mM} \mathrm{NaCl}, 10 \mathrm{mM}\left(\mathrm{NH}_{4}\right)_{2} \mathrm{SO}_{4}, 5 \mathrm{mM} \mathrm{MgSO} 4,1 \mathrm{mM}$ $\mathrm{CaCl}_{2}, 0.16 \mathrm{mM} \mathrm{KH}{ }_{2} \mathrm{PO}_{4}, 0.32 \mathrm{mM} \mathrm{K} \mathrm{HPO}_{4}, 0.01 \mathrm{mM} \mathrm{FeSO}$, $10 \mathrm{mM}$ fructose, $10 \mathrm{mM}$ sucrose, and $0.03 \%$ casamino acid) (Wengelnik et al. 1996) at $28^{\circ} \mathrm{C}$, P. syringae pv. tomato DC3000 $\Delta h r c U$ with $\mathrm{NYG}$ at $28^{\circ} \mathrm{C}$, and Agrobacterium tumefaciens strains with $\mathrm{LB}$ at $28^{\circ} \mathrm{C}$, with appropriate antibiotics. $\mathrm{LB}$ and NYG were supplemented with $1.5 \%$ (wt/vol) agar (LA and NYGA, respectively) for bacterial growth on plates. Antibiotics were used at the following final concentrations: carbenicillin $\left(50 \mu \mathrm{g} \mathrm{ml}^{-1}\right)$, chloramphenicol $\left(25 \mu \mathrm{g} \mathrm{ml}^{-1}\right)$, cyclohexamide $\left(50 \mu \mathrm{g} \mathrm{ml}^{-1}\right)$, kanamycin $\left(50 \mu \mathrm{g} \mathrm{ml}^{-1}\right)$, rifampicin $(100 \mu \mathrm{g}$ $\left.\mathrm{ml}^{-1}\right)$, spectinomycin $\left(50 \mu \mathrm{g} \mathrm{ml}^{-1}\right)$, and tetracycline $\left(5 \mu \mathrm{g} \mathrm{ml}^{-1}\right.$ for A. tumefaciens and $10 \mu \mathrm{g} \mathrm{ml}^{-1}$ for $X$. euvesicatoria). Plasmids were introduced into $E$. coli and $A$. tumefaciens by heat shock transformation and into $X$. euvesicatoria by triparental mating using E. coli HB101, pRK600 (Kessler et al. 1992).

\section{Plant materials.}

Seed from $N$. benthamiana and tomato (S. lycopersicum) 'VF36', 'Hawaii 7998', 'Hawaii 7981', and 'VF36' Bs2 were germinated in soil at room temperature (RT) under $16 \mathrm{~h}$ of light. After germination, tomato plants were grown in a greenhouse (16 h of light, 25 to $28^{\circ} \mathrm{C}$ ) and $N$. benthamiana in a growth chamber $\left(16 \mathrm{~h}\right.$ of light, $\left.25^{\circ} \mathrm{C}\right)$. For experiments, 4- to 6-weekold tomato and 6- to 8-week-old $N$. benthamiana plants were used.

\section{Genetic complementation of $\Delta x o p X$.}

The xopX locus from $X$. euvesicatoria 85-10 (including 387 bp upstream and $355 \mathrm{bp}$ downstream of the $x o p X$ coding sequence) was cloned by PCR using the primer pair RK2-1/ WS2-12 (Table 2) and ligated into pCR8 (Life Technologies, Carlsbad, CA, U.S.A.), creating pCR8( $\left.x o p X_{2623}\right)$. The $x o p X$ locus from pCR8 $\left(x o p X_{2623}\right)$ was then subcloned into pDSK519 by digesting pCR8 $\left(x o p X_{2623}\right)$ with EcoRI to obtain the $x o p X$ fragment; then, ligating this fragment into the EcoRI site of pDSK519 created pDSK519 $\left(x \circ p X_{2623}\right)$. pDSK519 $\left(x \circ p X_{2623}\right)$ was then introduced into $\triangle x o p X$ by triparental mating and selection of exconjugates with kanamycin.

\section{$X$. euvesicatoria growth in tomato leaves.}

$X$. euvesicatoria strains grown for $48 \mathrm{~h}$ on NYGA were resuspended in $1 \mathrm{mM} \mathrm{MgCl} 2$ and diluted to $1 \times 10^{5} \mathrm{CFU} \mathrm{ml}^{-1}$ (for low-titer inoculation in tomato 'VF36'), $2 \times 10^{8} \mathrm{CFU} \mathrm{ml}^{-1}$ (for high-titer inoculation in tomato 'VF36'), or $2 \times 10^{4} \mathrm{CFU}$ $\mathrm{ml}^{-1}$ (for low-titer inoculation in tomato 'Hawaii 7998' and 'Hawaii 7981'). X. euvesicatoria suspensions were infiltrated into the apoplastic space of tomato leaves using a needleless syringe. To quantify $X$. euvesicatoria bacterial population in leaf tissue, $0.5 \mathrm{~cm}^{2}$ of leaf tissue was harvested at $0,3,6$, and 9 $\mathrm{dpi}$, ground completely in $1 \mathrm{ml}$ of $1 \mathrm{mM} \mathrm{MgCl}_{2}$, serially diluted in $1 \mathrm{mM} \mathrm{MgCl}$, and plated on NYGA with appropriate antibiotics. $X$. euvesicatoria CFUs on plates were counted after $48 \mathrm{~h}$ of incubation at $28^{\circ} \mathrm{C}$.

\section{Preparation of $X$. euvesicatoria culture for protein expression.}

Individual $X$. euvesicatoria colonies were isolated on NYGA and cultured in NYG for $24 \mathrm{~h}$ at $28^{\circ} \mathrm{C}$ with shaking. Cellular pellets were collected by centrifugation $(8,000 \times g, 5 \mathrm{~min}, \mathrm{RT})$, resuspended in $1 \mathrm{mM} \mathrm{MgCl}$, collected again by centrifugation, and resuspended in NYG or XVM2 at a final titer of $4 \times 10^{8}$ $\mathrm{CFU} \mathrm{ml}{ }^{-1}$. Cultures were incubated for 2 to $4 \mathrm{~h}$ at $28^{\circ} \mathrm{C}$ with shaking. The optical density at $600 \mathrm{~nm}\left(\mathrm{OD}_{600}\right)$ of final cultures was measured using a spectrophotometer and cellular pellets were collected by centrifugation $(16,000 \times g, 2 \mathrm{~min}, \mathrm{RT})$.

\section{Agrobacterium-mediated transient protein expression in $N$. benthamiana.}

A. tumefaciens grown for 24 to $48 \mathrm{~h}$ on LA plates was resuspended in LB. Pellets were collected by centrifugation

Table 2. Primers used

\begin{tabular}{|c|c|c|}
\hline Target & Primer name and sequence $^{\mathrm{a}}$ & Reference \\
\hline \multicolumn{3}{|l|}{ For cloning xopX } \\
\hline \multirow[t]{2}{*}{ xopX } & CA359: ATGGAGATCAAGAAACAGCAAACC & This work \\
\hline & CA360: GGACGAAGGCACAGTGCTGGCTGCGGCCT & \\
\hline \multirow{2}{*}{$x o p X_{2623}$} & RK2-1: CAATGCGCTGCAACGACGCCTG & This work \\
\hline & WS2-12: ACAAGGTCAAGGAAGGCAGCGG & \\
\hline \multirow{3}{*}{$\begin{array}{l}\text { For deleting avrRxv } \\
\text { avrRxv upstream }\end{array}$} & & \\
\hline & WS1-40: TTGCCCTTGATGCCGCCGTT & This work \\
\hline & JG767: GAAGCTTAAGGATCCATATTTATTAGATCGCGCTAATCG & \\
\hline \multirow[t]{2}{*}{ avrRxv downstream } & 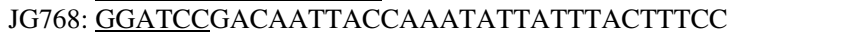 & This work \\
\hline & WS1-41: GAAGCTTATTGCCGATGCCGATGCTGG & \\
\hline \multicolumn{3}{|c|}{ For quantitative polymerase chain reaction } \\
\hline \multirow[t]{2}{*}{ SIACTIN } & JG234: GAGCGTGGTTACTCGTTCA & Kim et al. 2008 \\
\hline & JG136: CTAATATCCACGTCACATTTCAT & \\
\hline \multirow[t]{2}{*}{ SlPti5 } & CA305: ATTCGCGATTCGGCTAGACATGGT & Kim et al. 2009; Nguyen et al. 2010 \\
\hline & CA306: AGTAGTGCCTTAGCACCTCGCATT & \\
\hline \multirow[t]{2}{*}{ SlLRR22 } & CA293: AAGATTGGAGGTTGCCATTGGAGC & Kim et al. 2009; Nguyen et al. 2010 \\
\hline & CA294: ATCGCGATGAATGATCGGTGGAGT & \\
\hline \multirow[t]{2}{*}{ SIGRAS2 } & CA295: TAATCCAAGGGATGAGCTTCT & Kim et al. 2009; Nguyen et al. 2010 \\
\hline & CA296: CCACCAACGTGACCACCTT & \\
\hline \multirow[t]{2}{*}{ SlWRKY28 } & CA301: ACAGATGCAGCTACCTCATCCTCA & Kim et al. 2009; Nguyen et al. 2010 \\
\hline & CA302: GTGCTCAAAGCCTCATGGTTCTTG & \\
\hline \multirow[t]{2}{*}{$\mathrm{NbPP} 2 \mathrm{~A}$} & WS252:GACCCTGATGTTGATGTTCGCT & Nguyen et al. 2010 \\
\hline & WS253: GAGGGATTTGAAGAGAGATTTC & \\
\hline \multirow[t]{2}{*}{ NbAcre 31} & WS258: AATTCGGCCATCGTGATCTTGGTC & Nguyen et al. 2010 \\
\hline & WS259: GAGAAACTGGGATTGCCTGAAGGA & \\
\hline \multirow[t]{2}{*}{ NbPti5 } & WS256: CCTCCAAGTTTGAGCTCGGATAGT & Nguyen et al. 2010 \\
\hline & WS257: CCAAGAAATTCTCCATGCACTCTGTC & \\
\hline
\end{tabular}

${ }^{a}$ Restriction sites are underlined. 
$(8,000 \times g, 2 \mathrm{~min}, \mathrm{RT})$ and resuspended after removing supernatant in Agrobacterium induction medium (10 mM MES [pH 5.6], $10 \mathrm{mM} \mathrm{MgCl}$, and $150 \mu \mathrm{M}$ acetosyringone). For expression of GFP or GFP:XopX alone, A. tumefaciens was resuspended at a final titer of $4 \times 10^{8} \mathrm{CFU} \mathrm{ml} \mathrm{m}^{-1}$. Final A. tumefaciens concentrations in Pto-AvrPto co-inoculations were $2 \times 10^{8} \mathrm{CFU}$ $\mathrm{ml}^{-1}$ for all strains. Final A. tumefaciens concentrations in MAPK component co-inoculations were $2 \times 10^{8} \mathrm{CFU} \mathrm{ml} \mathrm{m}^{-1}$ (GFP, GFP:XopX, SIMPK1, empty) or $1 \times 10^{8} \mathrm{CFU} \mathrm{ml^{-1 }}$ (SIMAPKKK $\alpha, S I M K K 2^{\mathrm{DD}}$ ). Final A. tumefaciens concentrations in Bax co-inoculations were $4 \times 10^{8} \mathrm{CFU} \mathrm{ml}^{-1}$ for all strains. Descriptions and references for all strains and plasmids used are provided in Table 1. Briefly, GFP and GFP:XopX constructs were driven by the $35 \mathrm{~S}$ promoter and borne on binary vector pGWB6 in A. tumefaciens C58C1(pCH32). Pto-AvrPto was driven by the $35 S$ promoter and borne on pBTEX in $A$. tumefaciens EHA105. MAPK components have a C-terminal $\mathrm{HA}$ tag and were driven by an estradiol-inducible promoter and borne on pER8 in A. tumefaciens GV2260. Bax was driven by the $35 \mathrm{~S}$ promoter and borne on $\mathrm{pBTEX}$ in A. tumefaciens GV2260.

Final A. tumefaciens suspensions were syringe infiltrated into $N$. benthamiana leaves using a needleless syringe. For estradiolinducible constructs, $5 \mu \mathrm{M} 17-\beta$ estradiol with $0.05 \%$ Tween-20 was applied by spraying leaves $24 \mathrm{~h}$ after initial $A$. tumefaciens infiltration. Infiltrated plants were placed under continuous light at RT for the duration of all experiments.

\section{Analysis of protein expression.}

Protein levels from $X$. euvesicatoria cultures and transient expression in $N$. benthamiana were analyzed by immunoblot, essentially as previously described (Mudgett and Staskawicz 1999). For X. euvesicatoria cultures, collected cellular pellets were denatured in urea sample buffer $(8 \mathrm{M}$ urea, $15 \% \beta$-mercaptoethanol, $60 \mathrm{mM}$ Tris [pH 6.8], 2\% sodium dodecyl sulfate [SDS], $11.8 \%$ glycerol, $0.0013 \%$ bromophenol blue, and protease inhibitor cocktail at $25 \mathrm{nl} \mathrm{ml}^{-1}$ ) (Sigma-Aldrich, St. Louis) using $100 \mu \mathrm{l}$ per $1 \mathrm{OD}_{600}$ unit ( $1 \mathrm{ml}$ of $X$. euvesicatoria culture at $1 \mathrm{OD}_{600}=1 \mathrm{OD}_{600}$ unit). For $N$. benthamiana, leaf tissue was completely disrupted in urea sample buffer. Total protein was separated by SDS-polyacrylamide gel electrophoresis (PAGE) and transferred to nitrocellulose membrane. Protein was detected by ECL Plus (GE Healthcare, Buckinghamshire, United Kingdom) after blotting membranes with rabbit anti-XopX antisera (Covance, Denver, PA, U.S.A.), mouse anti-HA antibody (Covance, Berkeley, CA, U.S.A.), or mouse anti-GFP antibody (Clontech, Mountain View, CA, U.S.A.) followed by horseradish-peroxidase-conjugated secondary antibodies (Bio-Rad, Hercules, CA, U.S.A.). The anti-XopX antisera were generated against recombinant, full-length XopX with an N-terminal hexa-histidine tag expressed in $E$. coli off of pDEST17(xopX), batch purified with nickel-NTA resin under denaturing conditions $\left(100 \mathrm{mM} \mathrm{NaH} \mathrm{PO}_{4}, 10 \mathrm{mM}\right.$ Tris $\mathrm{HCl}, 8 \mathrm{M}$ urea [pH 8.0 for lysis, $\mathrm{pH} 6.3$ for wash, and $\mathrm{pH} 4.5$ for elution], $10 \mathrm{mM}$ imidazole for lysis, and $20 \mathrm{mM}$ imidazole for wash or elution), and separated by SDS-PAGE.

\section{Trypan blue staining for PCD.}

Sample preparation prior to trypan blue staining in $N$. benthamiana and tomato experiments differed slightly. For $N$. benthamiana, transient expression of GFP or GFP:XopX was performed in different regions of the same leaf using A. tumefaciens at $4 \times 10^{8} \mathrm{CFU} \mathrm{ml}^{-1}$. The whole leaf was harvested at 3 dpi, photographed, and subjected to trypan blue staining. For tomato, $X$. euvesicatoria $\mathrm{WT}$ and $\Delta x o p X$ were inoculated into different regions of the same leaf at $2 \times 10^{8} \mathrm{CFU} \mathrm{ml}{ }^{-1}$. Whole leaves were harvest at 1, 2, and 3 dpi, photographed, and sub- jected to trypan blue staining. Trypan blue staining was performed as described (van Wees 2008), with slight modifications. Whole leaves were completely submerged in $50 \mathrm{ml}$ of staining solution (67\% ethanol, 8.3\% lactic acid, $8.3 \%$ phenol, $8.3 \%$ glycerol, and trypan blue at $2.5 \mathrm{mg} \mathrm{ml}^{-1}$ ), boiled for 5 min, and incubated overnight $(\mathrm{O} / \mathrm{N})$ at RT. Leaves were transferred to destaining solution (67\% ethanol, $8.3 \%$ lactic acid, $8.3 \%$ phenol, and $8.3 \%$ glycerol) $\mathrm{O} / \mathrm{N}$ at RT with gentle shaking. Leaves were washed in ethanol, dried briefly, and photographed. Regions of dark blue indicate uptake of trypan blue by dead and dying cells.

\section{Electrolyte leakage quantification.}

Electrolyte leakage quantification in $N$. benthamiana and tomato experiments differed slightly. For $N$. benthamiana, transient expression of GFP or GFP:XopX was performed in different regions of the same leaf using $A$. tumefaciens at $4 \times 10^{8}$ $\mathrm{CFU} \mathrm{ml} \mathrm{m}^{-1}$. Four leaf disks (12 $\mathrm{mm}$ in diameter) were sampled from each inoculation region at $20 \mathrm{hpi}$, rinsed in distilled water, and floated on $5 \mathrm{ml}$ of distilled water in a six-well tissue plate under continuous light. At $24 \mathrm{~h}$ after initial A. tumefaciens inoculation, conductivity of the bathing water was measured using a conductivity meter, and repeated every subsequent $24 \mathrm{~h}$. Mean conductivity \pm standard deviation (SD) from three plants is reported for each treatment. For tomato, $X$. euvesicatoria strains were inoculated into different leaflets of the same leaf at $2 \times 10^{8} \mathrm{CFU} \mathrm{ml}^{-1}$. Leaf disks ( 4 by $12 \mathrm{~mm}$ in diameter for 'VF36', 5 by $8 \mathrm{~mm}$ in diameter for 'Hawaii 7998' and 'VF36' Bs2) were sampled at indicated times (24, 48, and 72 hpi for 'VF36'; 16 and 24 hpi for 'Hawaii 7998' and 'VF36' Bs2), rinsed in distilled water, and floated on $5 \mathrm{ml}$ (VF36) or $3 \mathrm{ml}$ ('Hawaii 7998' and 'VF36' Bs2) of distilled water for $4 \mathrm{~h}$ with gentle shaking. Conductivity of the bathing water was then measured. Mean conductivity \pm SD from three plants is reported for each treatment.

\section{ET quantification.}

Sample preparation prior to ET quantification in N. benthamiana and tomato experiments differed slightly. For N. benthamiana, transient expression of GFP or GFP:XopX was performed on two halves of the same leaf, divided by the midvein, using A. tumefaciens at $4 \times 10^{8} \mathrm{CFU} \mathrm{ml}^{-1}$. Whole leaves were excised and GFP- and GFP:XopX-expressing halves were separated by cutting along the midvein. For tomato, $X$. euvesicatoria strains were inoculated into different leaflets of the same

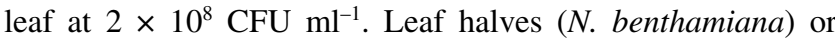
leaflets (tomato) were weighed, placed in a glass tube capped with a Suba-Seal septa stopper (Sigma-Aldrich), and incubated for $1 \mathrm{~h}$ at $25^{\circ} \mathrm{C}$. A $1-\mathrm{ml}$ gas sample was injected into a gas chromatograph and ET levels were quantified. Mean ET \pm SD from three ( $N$. benthamiana) or four (tomato) plants is reported for each treatment.

\section{SA quantification.}

SA quantification was performed as described (Defraia et al. 2008), with slight modifications. Sample preparation prior to SA quantification in $N$. benthamiana and tomato experiments differed slightly. For $N$. benthamiana, transient expression of GFP or GFP:XopX was performed on different regions of the

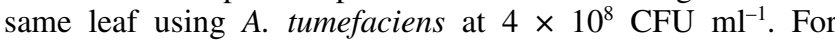
tomato, $X$. euvesicatoria strains were inoculated into different leaflets of the same leaf at $2 \times 10^{8} \mathrm{CFU} \mathrm{ml}^{-1}$. Inoculated leaf tissue $(50 \mathrm{mg})$ was excised and homogenized in $500 \mu \mathrm{l}$ of 0.1 $\mathrm{M}$ acetate buffer, $\mathrm{pH}$ 5.6. Samples were centrifuged $(16,000 \times$ $\left.g, 15 \mathrm{~min}, 4^{\circ} \mathrm{C}\right), 100 \mu \mathrm{l}$ of supernatant was transferred to a new tube for free SA quantification, and $50 \mu \mathrm{l}$ of supernatant was incubated with $5 \mu \mathrm{l}$ of $\beta$-glucosidase (Sigma-Aldrich) at $0.4 \mathrm{U}$ 
$\mu \mathrm{l}^{-1}$ for $90 \mathrm{~min}$ at $37^{\circ} \mathrm{C}$ for total SA quantification. In all, $60 \mu \mathrm{l}$ of LB, $20 \mu \mathrm{l}$ of extract, and $50 \mu \mathrm{l}$ of Acinetobacter sp. ADPWH_lux (Huang et al. 2005) were added to each well of a black 96-well plate at $4 \times 10^{8} \mathrm{CFU} \mathrm{ml}^{-1}$. The plate was incubated at $37^{\circ} \mathrm{C}$ for $60 \mathrm{~min}$; then, luminescence was measured using a plate reader with luminometer function. To generate a standard curve, $1 \mu \mathrm{l}$ of SA standard solution was diluted 10 fold in untreated leaf extract from $N$. benthamiana or tomato 'Moneymaker' nahG (Brading et al. 2000). In total, $5 \mu \mathrm{l}$ of each standard was added to $60 \mu \mathrm{l}$ of LB and $50 \mu \mathrm{l}$ of Acinetobacter sp. ADPWH_lux $\left(4 \times 10^{8} \mathrm{CFU} \mathrm{ml^{-1 }}\right)$ and luminescence was measured at the same time as experimental samples. Mean SA (free or total) \pm SD from three $(N$. benthamiana) or four (tomato) plants is reported for each treatment.

\section{Quantification of plant gene transcript abundance by reverse-transcriptase qPCR.}

Sample preparation prior to transcript quantification in $N$. benthamiana and tomato experiments differed slightly. For $N$. benthamiana, transient expression of GFP or GFP:XopX was performed on different regions of the same leaf using A. tumefaciens at $4 \times 10^{8} \mathrm{CFU} \mathrm{ml}^{-1}$. At $24 \mathrm{hpi}$, GFP- and GFP:XopXexpressing regions were inoculated with $1 \mathrm{mM} \mathrm{MgCl}_{2}$ (mock) or $P$. syringae pv. tomato $\Delta h r c U$ at $2 \times 10^{8} \mathrm{CFU} \mathrm{ml}^{-1}$. For tomato, $X$. euvesicatoria strains were inoculated into different leaflets of the same leaf at $2 \times 10^{8} \mathrm{CFU} \mathrm{ml}^{-1}$. Leaf tissue was excised and total RNA was extracted using TRI Reagent (Life Technologies). RNA ( $5 \mu \mathrm{g}$ ) was used for cDNA synthesis with poly-T primers and Maxima Reverse Transcriptase (Thermo Scientific, Waltham, MA, U.S.A.).

qPCR of cDNA was performed on MJ Opticon 2 (Bio-Rad) using SYBR Green reporter (Thermo Scientific) with genespecific primers (Table 2). Relative fold changes in gene transcript abundance were determined by the comparative cycle threshold $\left(\mathrm{C}_{\mathrm{T}}\right)$ method (Livak and Schmittgen 2001). $\mathrm{C}_{\mathrm{T}}$ values were determined by the average of two technical replicates per gene per sample. Relative fold change for each gene was calibrated to the average $\Delta \mathrm{C}_{\mathrm{T}}$ values from mock $(1 \mathrm{mM} \mathrm{MgCl})$ treatments with $N b P P 2 A$ or SIACTIN used as the internal control. Mean $2^{-\Delta \Delta C T}$ values \pm SD for four plants are reported.

\section{Quantification of flg22-elicited ROS.}

Transient expression of GFP or GFP:XopX was performed on different regions of the same leaf using A. tumefaciens at $4 \times$ $10^{8} \mathrm{CFU} \mathrm{m}{ }^{-1}$. At $24 \mathrm{hpi}$, three leaf disks (4 mm in diameter) were excised from each inoculated region and floated in $200 \mu \mathrm{l}$ of sterile distilled water $\mathrm{O} / \mathrm{N}$ in a 96-well plate. To initiate the assay, water was removed and $100 \mu \mathrm{l}$ of solution (luminol at $34 \mu \mathrm{g} \mathrm{ml}^{-1}$ and horseradish peroxidase at $20 \mu \mathrm{g} \mathrm{ml}^{-1}$ ) with 200 nM flg22 (flg22) or without flg22 (mock) was added to each well. Using an automatic plate reader with luminometer function, luminescence from individual leaf disks was measured as relative light units (RLU) and recorded at regular intervals for approximately $90 \mathrm{~min}$ starting immediately after addition of solution. The time interval between plate reads was approximately $50 \mathrm{~s}$. For each sample, RLU measured at the indicated time point were averaged for three technical replicates from each biological replicate. Mean RLU \pm SD for four plants is reported.

\section{Scoring PCD phenotype in $N$. benthamiana after XopX coexpression with PCD elicitors.}

$N$. benthamiana leaves were co-inoculated with two A. tumefaciens strains to express GFP or GFP:XopX with PCD elicitors Pto-AvrPto, SIMAPKK $\alpha$, SIMKK2 ${ }^{\mathrm{DD}}$, SIMPK1, Bax, or appropriate empty vectors. For each experiment, co-inoculations were performed with the first three fully expanded leaves from each of six plants. For estradiol-inducible MAPK component constructs, $5 \mu \mathrm{M} 17-\beta$ estradiol with $0.05 \%$ Tween- 20 was applied by spraying leaves $24 \mathrm{~h}$ after initial A. tumefaciens infiltration. Inoculated leaf tissue was monitored for 3 to 5 days and each inoculated region was qualitatively scored for the amount of tissue collapse ( 0 to $10 \%$ collapse $=$ none or limited, 10 to $85 \%$ collapse $=$ partial, and $>85 \%$ collapse $=$ full $)$. The percentage of co-inoculated regions with each level of tissue collapse at 3 dpi (Pto-AvrPto or Bax) or 5 dpi (MAPK components) was compared between GFP and GFP:XopX treatments for each PCD elicitor.

\section{DAB staining of $N$. benthamiana leaves.}

$N$. benthamiana leaves were co-inoculated with two A. tumefaciens strains to express GFP or GFP:XopX with NtMEK2 $2^{\text {DD }}$. To induce NtMEK $2^{\mathrm{DD}}$ expression, $5 \mu \mathrm{M} 17-\beta$ estradiol with $0.05 \%$ Tween-20 was applied by spraying leaves $24 \mathrm{~h}$ after initial A. tumefaciens infiltration. At $10 \mathrm{~h}$ after estradiol treatment, inoculated regions were excised, submerged in staining solution (DAB at $1 \mathrm{mg} \mathrm{ml}^{-1}, 10 \mathrm{mM} \mathrm{K}_{2} \mathrm{HPO}_{4}$, and $0.05 \%$ Tween-20), subjected to vacuum for $5 \mathrm{~min}$, and incubated in the dark at RT for $4 \mathrm{~h}$. Leaf chlorophyll was cleared by floating the leaf in ethanol with gentle shaking for several days. Cellular accumulation of $\mathrm{H}_{2} \mathrm{O}_{2}$ was imaged using a light microscope under $\times 10$ magnification.

\section{Genomic deletion of avrRxv}

in $X$. euvesicatoria 85-10 and $\Delta x o p X$.

The genomic region $(1,567 \mathrm{bp})$ directly upstream of the avrRxv coding sequence was amplified by PCR with a $3^{\prime}$ BamHI::HindIII extension (primer pair WS01-40/JG767) and ligated into pCR8 (Life Technologies). The genomic region (1,594 bp) directly downstream of $a v r R x v$ was amplified as a BamHI-HindIII fragment (primer pair JG768/WS01-41) and blunt-end ligated into pJET1.2 (Thermo Scientific). The BamHIHindIII downstream fragment was then subcloned into the BamHI::HindIII site of the pCR8 vector containing the upstream fragment, generating the $\Delta a v r R x v$ construct. The $\Delta a v r R x v$ construct was then recombined using LR Clonase II (Life Technologies) into a Gateway-compatible version of the suicide vector pLVC18-Rfc, generating pLVC18-Rfc( $\Delta a v r R x v)$. $\mathrm{pLVC} 18-\operatorname{Rfc}(\Delta a v r R x v)$ was then introduced into $X$. euvesicatoria $85-10$ and $\Delta x o p X$ by triparental mating. Single-crossover exconjugates were first selected on tetracycline NYGA and then grown in NYG without tetracycline selection, with several subculturing steps. Cultures were diluted and plated on NYGA without tetracycline. Individual colonies were replica plated with and without tetracycline selection to identify tetracyclinesensitive double-crossover $\Delta a v r R x v$ mutants. Deletion of the avrRxv coding sequence in individual mutants was confirmed by colony PCR and by loss of the ability of mutants to induce the hypersensitive response in 'Hawaii 7998' tomato.

\section{ACKNOWLEDGMENTS}

We thank M. Soriano for technical assistance; S. Sonnewald for providing $\Delta x o p X ; \mathrm{G}$. Sessa for providing useful discussion, A. tumefaciens strains, and 'Hawaii 7998' and '7981' seed; members of the Mudgett Laboratory for feedback on this manuscript; and the laboratories of D. Bergmann, O. Gozani, S. Long, J. Sonnenburg, and V. Walbot for scientific discussions or use of equipment. W. Stork is supported by United States Department of Agriculture NIFA Grant 2012-67011-19669. M. B. Mudgett is supported by National Institutes of Health Grant 2 R01 GM068886-06A1.

\section{LITERATURE CITED}

Abramovitch, R. B., Kim, Y. J., Chen, S., Dickman, M. B., and Martin, G. B. 2003. Pseudomonas type III effector AvrPtoB induces plant disease 
susceptibility by inhibition of host programmed cell death. EMBO (Eur. Mol. Biol. Organ.) J. 22:60-69.

Axtell, M. J., and Staskawicz, B. J. 2003. Initiation of RPS2-specified disease resistance in Arabidopsis is coupled to the AvrRpt2-directed elimination of RIN4. Cell 112:369-377.

Badel, J. L., Shimizu, R., Oh, H. S., and Collmer, A. 2006. A Pseudomonas syringae pv. tomato avrE1/hopM1 mutant is severely reduced in growth and lesion formation in tomato. Mol. Plant-Microbe Interact. 19:99-111.

Bari, R., and Jones, J. D. 2009. Role of plant hormones in plant defence responses. Plant Mol. Biol. 69:473-488.

Boller, T., and He, S. Y. 2009. Innate immunity in plants: An arms race between pattern recognition receptors in plants and effectors in microbial pathogens. Science 324:742-744.

Bonas, U., Schulte, R., Fenselau, S., Minsavage, G. V., Staskawicz, B. J., and Stall, R. E. 1991. Isolation of a gene cluster from Xanthomonas campestris pv. vesicatoria that determines pathogenicity and the hypersensitive response on pepper and tomato. Mol. Plant-Microbe Interact. 4:81-88

Bonshtien, A., Lev, A., Gibly, A., Debbie, P., Avni, A., and Sessa, G. 2005 Molecular properties of the Xanthomonas AvrRxv effector and global transcriptional changes determined by its expression in resistant tomato plants. Mol. Plant-Microbe Interact. 18:300-310.

Brading, P. A., Hammond-Kosack, K. E., Parr, A., and Jones, J. D. 2000. Salicylic acid is not required for Cf-2- and Cf-9-dependent resistance of tomato to Cladosporium fulvum. Plant J. 23:305-318.

Buttner, D. 2012. Protein export according to schedule: Architecture, assembly, and regulation of type III secretion systems from plant- and animal-pathogenic bacteria. Microbiol. Mol. Biol. Rev. 76:262-310.

Cohn, J. R., and Martin, G. B. 2005. Pseudomonas syringae pv. tomato type III effectors AvrPto and AvrPtoB promote ethylene-dependent cell death in tomato. Plant J. 44:139-154.

Cunnac, S., Lindeberg, M., and Collmer, A. 2009. Pseudomonas syringae type III secretion system effectors: Repertoires in search of functions. Curr. Opin. Microbiol. 12:53-60.

Dangl, J. L., Horvath, D. M., and Staskawicz, B. J. 2013. Pivoting the plant immune system from dissection to deployment. Science 341:746-751.

Defraia, C. T., Schmelz, E. A., and Mou, Z. 2008. A rapid biosensor-based method for quantification of free and glucose-conjugated salicylic acid. Plant Methods 4:28.

del Pozo, O., Pedley, K. F., and Martin, G. B. 2004. MAPKKKalpha is a positive regulator of cell death associated with both plant immunity and disease. EMBO (Eur. Mol. Biol. Organ.) J. 23:3072-3082.

Doidge, E. M. 1921. A tomato canker. Ann. Appl. Biol. 7:407-430.

Feng, F., Yang, F., Rong, W., Wu, X., Zhang, J., Chen, S., He, C., and Zhou, J. M. 2012. A Xanthomonas uridine 5'-monophosphate transferase inhibits plant immune kinases. Nature 485:114-118.

Frederick, R. D., Thilmony, R. L., Sessa, G., and Martin, G. B. 1998 Recognition specificity for the bacterial avirulence protein AvrPto is determined by Thr-204 in the activation loop of the tomato Pto kinase. Mol. Cell 2:241-245.

Gimenez-Ibanez, S., Hann, D. R., Ntoukakis, V., Petutschnig, E., Lipka, V., and Rathjen, J. P. 2009. AvrPtoB targets the LysM receptor kinase CERK1 to promote bacterial virulence on plants. Curr. Biol. 19:423429.

Gohre, V., Spallek, T., Haweker, H., Mersmann, S., Mentzel, T., Boller, T., de Torres, M., Mansfield, J. W., and Robatzek, S. 2008. Plant patternrecognition receptor FLS2 is directed for degradation by the bacterial ubiquitin ligase AvrPtoB. Curr. Biol. 18:1824-1832.

Guo, M., Tian, F., Wamboldt, Y., and Alfano, J. R. 2009. The majority of the type III effector inventory of Pseudomonas syringae pv. tomato DC3000 can suppress plant immunity. Mol. Plant-Microbe Interact. 22:1069-1080.

Hajri, A., Brin, C., Hunault, G., Lardeux, F., Lemaire, C., Manceau, C., Boureau, T., and Poussier, S. 2009. A "repertoire for repertoire" hypothesis: Repertoires of type three effectors are candidate determinants of host specificity in Xanthomonas. PLoS One 4:e6632. Published online.

Ham, J. H., Majerczak, D. R., Nomura, K., Mecey, C., Uribe, F., He, S. Y. Mackey, D., and Coplin, D. L. 2009. Multiple activities of the plant pathogen type III effector proteins WtsE and AvrE require WxxxE motifs. Mol. Plant-Microbe Interact. 22:703-712.

He, K., Gou, X., Yuan, T., Lin, H., Asami, T., Yoshida, S., Russell, S. D., and Li, J. 2007. BAK1 and BKK1 regulate brassinosteroid-dependent growth and brassinosteroid-independent cell-death pathways. Curr. Biol. 17:1109-1115.

Hood, E. E., Gelvin, S. B., Melchers, L. S., and Hoekema, A. 1993. New Agrobacterium helper plasmids for gene transfer to plants. Transgenic Res. 2:208-218.

Huang, W. E., Wang, H., Zheng, H., Huang, L., Singer, A. C., Thompson, I., and Whiteley, A. S. 2005. Chromosomally located gene fusions con- structed in Acinetobacter sp. ADP1 for the detection of salicylate. Environ. Microbiol. 7:1339-1348.

Jalan, N., Aritua, V., Kumar, D., Yu, F., Jones, J. B., Graham, J. H. Setubal, J. C., and Wang, N. 2011. Comparative genomic analysis of Xanthomonas axonopodis pv. citrumelo F1, which causes citrus bacterial spot disease, and related strains provides insights into virulence and host specificity. J. Bacteriol. 193:6342-6357.

Jamir, Y., Guo, M., Oh, H. S., Petnicki-Ocwieja, T., Chen, S., Tang, X., Dickman, M. B., Collmer, A., and Alfano, J. R. 2004. Identification of Pseudomonas syringae type III effectors that can suppress programmed cell death in plants and yeast. Plant J. 37:554-565.

Jones, J. B., Stall, R. E., and Bouzar, H. 1998. Diversity among xanthomonads pathogenic on pepper and tomato. Annu. Rev. Phytopathol. 36:41-58

Jones, J. B., Lacy, G. H., Bouzar, H., Stall, R. E., and Schaad, N. W. 2004 Reclassification of the xanthomonads associated with bacterial spot disease of tomato and pepper. Syst. Appl. Microbiol. 27:755-762.

Jones, J. D., and Dangl, J. L. 2006. The plant immune system. Nature 444:323-329.

Kadota, Y., Sklenar, J., Derbyshire, P., Stransfeld, L., Asai, S., Ntoukakis, V., Jones, J. D., Shirasu, K., Menke, F., Jones, A., and Zipfel, C. 2014. Direct regulation of the NADPH oxidase RBOHD by the PRR-associated kinase BIK1 during plant immunity. Mol. Cell 54:43-55.

Kawai-Yamada, M., Ohori, Y., and Uchimiya, H. 2004. Dissection of Arabidopsis Bax inhibitor-1 suppressing Bax-, hydrogen peroxide-, and salicylic acid-induced cell death. Plant Cell 16:21-32.

Keen, N. T., Tamaki, S., Kobayashi, D., and Trollinger, D. 1988. Improved broad-host-range plasmids for DNA cloning in gram-negative bacteria. Gene 70:191-197.

Kemmerling, B., Schwedt, A., Rodriguez, P., Mazzotta, S., Frank, M., Qamar, S. A., Mengiste, T., Betsuyaku, S., Parker, J. E., Mussig, C., Thomma, B. P., Albrecht, C., de Vries, S. C., Hirt, H., and Nurnberger, T. 2007. The BRI1-associated kinase 1, BAK1, has a brassinolide-independent role in plant cell-death control. Curr. Biol. 17:1116-1122.

Kessler, B., de Lorenzo, V., and Timmis, K. N. 1992. A general system to integrate lac $Z$ fusions into the chromosomes of gram-negative eubacteria: Regulation of the $P m$ promoter of the TOL plasmid studied with all controlling elements in monocopy. Mol. Gen. Genet. 233:293-301.

Kim, H. S., Desveaux, D., Singer, A. U., Patel, P., Sondek, J., and Dangl, J. L. 2005. The Pseudomonas syringae effector AvrRpt2 cleaves its Cterminally acylated target, RIN4, from Arabidopsis membranes to block RPM1 activation. Proc. Natl. Acad. Sci. U.S.A. 102:6496-6501.

Kim, J. G., Taylor, K. W., Hotson, A., Keegan, M., Schmelz, E. A., and Mudgett, M. B. 2008. XopD SUMO protease affects host transcription, promotes pathogen growth, and delays symptom development in Xanthomonas-infected tomato leaves. Plant Cell 20:1915-1929.

Kim, J. G., Li, X., Roden, J. A., Taylor, K.W., Aakre, C. D., Su, B., Lalonde, S., Kirik, A., Chen, Y., Baranage, G., McLane, H., Martin, G. B., and Mudgett, M. B. 2009. Xanthomonas T3S effector XopN suppresses PAMP-triggered immunity and interacts with a tomato atypical receptor-like kinase and TFT1. Plant Cell 21:1305-1323.

Kim, J. G., Stork, W., and Mudgett, M. B. 2013. Xanthomonas type III effector XopD desumoylates tomato transcription factor SIERF4 to suppress ethylene responses and promote pathogen growth. Cell Host Microbe 13:143-154.

Kunkel, B. N., and Brooks, D. M. 2002. Cross talk between signaling pathways in pathogen defense. Curr. Opin. Plant Biol. 5:325-331.

Lindeberg, M., Cunnac, S., and Collmer, A. 2012. Pseudomonas syringae type III effector repertoires: Last words in endless arguments. Trends Microbiol. 20:199-208.

Liu, Y., Ren, D., Pike, S., Pallardy, S., Gassmann, W., and Zhang, S. 2007. Chloroplast-generated reactive oxygen species are involved in hypersensitive response-like cell death mediated by a mitogen-activated protein kinase cascade. Plant J. 51:941-954.

Livak, K. J., and Schmittgen, T. D. 2001. Analysis of relative gene expression data using real-time quantitative PCR and the 2(-Delta Delta C(T)) Method. Methods 25:402-408.

Lund, S. T., Stall, R. E., and Klee, H. J. 1998. Ethylene regulates the susceptible response to pathogen infection in tomato. Plant Cell 10:371-382.

Mackey, D., Holt, B. F., 3rd, Wiig, A., and Dangl, J. L. 2002. RIN4 interacts with Pseudomonas syringae type III effector molecules and is required for RPM1-mediated resistance in Arabidopsis. Cell 108:743-754.

Mackey, D., Belkhadir, Y., Alonso, J. M., Ecker, J. R., and Dangl, J. L. 2003. Arabidopsis RIN4 is a target of the type III virulence effector AvrRpt2 and modulates RPS2-mediated resistance. Cell 112:379-389.

McBride, K. E., and Summerfelt, K. R. 1990. Improved binary vectors for Agrobacterium-mediated plant transformation. Plant Mol. Biol. 14:269276.

Metz, M., Dahlbeck, D., Morales, C. Q., Al Sady, B., Clark, E. T., and Staskawicz, B. J. 2005. The conserved Xanthomonas campestris pv. 
vesicatoria effector protein $\mathrm{XopX}$ is a virulence factor and suppresses host defense in Nicotiana benthamiana. Plant J. 41:801-814.

Minsavage, G. V., Dahlbeck, D., Whalen, M. C., Kearney, B., Bonas, U., Staskawicz, B. J., and Stall, R. E. 1990. Gene-for-gene relationships specifying disease resistance in Xanthomonas campestris pv. vesicatoria-pepper interactions. Mol. Plant-Microbe Interact. 3:41-47.

Moreira, L. M., Almeida, N. F., Jr., Potnis, N., Digiampietri, L. A., Adi, S. S., Bortolossi, J. C., da Silva, A. C., da Silva, A. M., de Moraes, F. E., de Oliveira, J. C., de Souza, R. F., Facincani, A. P., Ferraz, A. L., Ferro, M. I., Furlan, L. R., Gimenez, D. F., Jones, J. B., Kitajima, E. W., Laia, M. L., Leite, R. P., Jr., Nishiyama, M. Y., Rodrigues Neto, J., Nociti, L. A., Norman, D. J., Ostroski, E. H., Pereira, H. A., Jr., Staskawicz, B. J., Tezza, R. I., Ferro, J. A., Vinatzer, B. A., and Setubal, J. C. 2010. Novel insights into the genomic basis of citrus canker based on the genome sequences of two strains of Xanthomonas fuscans subsp. aurantifolii. BMC Genomics 11:238.

Mudgett, M. B., and Staskawicz, B. J. 1999. Characterization of the Pseudomonas syringae pv. tomato AvrRpt 2 protein: Demonstration of secretion and processing during bacterial pathogenesis. Mol. Microbiol. 32:927-941.

Mukhtar, M. S., Carvunis, A. R., Dreze, M., Epple, P., Steinbrenner, J., Moore, J., Tasan, M., Galli, M., Hao, T., Nishimura, M. T., Pevzner, S. J., Donovan, S. E., Ghamsari, L., Santhanam, B., Romero, V., Poulin, M. M., Gebreab, F., Gutierrez, B. J., Tam, S., Monachello, D., Boxem, M., Harbort, C.J., McDonald, N., Gai, L., Chen, H., He, Y., Vandenhaute, J., Roth, F. P., Hill, D. E., Ecker, J. R., Vidal, M., Beynon, J., Braun, P., and Dangl, J. L. 2011. Independently evolved virulence effectors converge onto hubs in a plant immune system network. Science 333:596-601.

Nakagawa, T., Kurose, T., Hino, T., Tanaka, K., Kawamukai, M., Niwa, Y., Toyooka, K., Matsuoka, K., Jinbo, T., and Kimura, T. 2007. Develop-

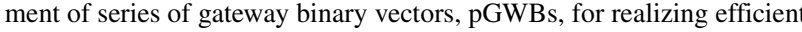
construction of fusion genes for plant transformation. J. Biosci. Bioeng. 104:34-41.

Nguyen, H. P., Chakravarthy, S., Velasquez, A. C., McLane, H. L., Zeng, L., Nakayashiki, H., Park, D. H., Collmer, A., and Martin, G. B. 2010. Methods to study PAMP-triggered immunity using tomato and Nicotiana benthamiana. Mol. Plant-Microbe Interact. 23:991-999.

Nishimura, M. T., Stein, M., Hou, B. H., Vogel, J. P., Edwards, H., and Somerville, S. C. 2003. Loss of a callose synthase results in salicylic acid-dependent disease resistance. Science 301:969-972.

Nomura, K., Debroy, S., Lee, Y. H., Pumplin, N., Jones, J., and He, S. Y. 2006. A bacterial virulence protein suppresses host innate immunity to cause plant disease. Science 313:220-223.

O’Donnell, P. J., Jones, J. B., Antoine, F. R., Ciardi, J., and Klee, H. J. 2001. Ethylene-dependent salicylic acid regulates an expanded cell death response to a plant pathogen. Plant J. 25:315-323.

O’Donnell, P. J., Schmelz, E., Block, A., Miersch, O., Wasternack, C., Jones, J. B., and Klee, H. J. 2003. Multiple hormones act sequentially to mediate a susceptible tomato pathogen defense response. Plant Physiol. 133:1181-1189.

Oh, C. S., and Martin, G. B. 2011a. Effector-triggered immunity mediated by the Pto kinase. Trends Plant Sci. 16:132-140.

Oh, C. S., and Martin, G. B. 2011b. Tomato 14-3-3 protein TFT7 interacts with a MAP kinase kinase to regulate immunity-associated programmed cell death mediated by diverse disease resistance proteins. J. Biol. Chem. 286:14129-14136.

Pedley, K. F., and Martin, G. B. 2004. Identification of MAPKs and their possible MAPK kinase activators involved in the Pto-mediated defense response of tomato. J. Biol. Chem. 279:49229-49235.

Petersen, M., Brodersen, P., Naested, H., Andreasson, E., Lindhart, U., Johansen, B., Nielsen, H. B., Lacy, M., Austin, M. J., Parker, J. E., Sharma, S. B., Klessig, D. F., Martienssen, R., Mattsson, O., Jensen, A. B., and Mundy, J. 2000. Arabidopsis MAP Kinase 4 negatively regulates systemic acquired resistance. Cell 103:1111-1120.

Potnis, N., Krasileva, K., Chow, V., Almeida, N. F., Patil, P. B., Ryan, R. P., Sharlach, M., Behlau, F., Dow, J. M., Momol, M., White, F. F., Preston, J. F., Vinatzer, B. A., Koebnik, R., Setubal, J. C., Norman, D. J., Staskawicz, B. J., and Jones, J. B. 2011. Comparative genomics reveals diversity among xanthomonads infecting tomato and pepper. BMC Genomics $12: 146$.

Reuber, T. L., and Ausubel, F. M. 1996. Isolation of Arabidopsis genes that differentiate between resistance responses mediated by the RPS 2 and RPM1 disease resistance genes. Plant Cell 8:241-249.

Ritter, C., and Dangl, J. L. 1996. Interference between two specific pathogen recognition events mediated by distinct plant disease resistance genes. Plant Cell 8:251-257.

Roden, J. A., Belt, B., Ross, J. B., Tachibana, T., Vargas, J., and Mudgett, M. B. 2004. A genetic screen to isolate type III effectors translocated into pepper cells during Xanthomonas infection. Proc. Natl. Acad. Sci. U.S.A. 101:16624-16629.

Rossier, O., Wengelnik, K., Hahn, K., and Bonas, U. 1999. The Xanthomonas Hrp type III system secretes proteins from plant and mammalian bacterial pathogens. Proc. Natl. Acad. Sci. U.S.A. 96:9368-9373.

Salomon, D., Dar, D., Sreeramulu, S., and Sessa, G. 2011. Expression of Xanthomonas campestris pv. vesicatoria type III effectors in yeast affects cell growth and viability. Mol. Plant-Microbe Interact. 24:305-314.

Sato, M., Tsuda, K., Wang, L., Coller, J., Watanabe, Y., Glazebrook, J., and Katagiri, F. 2010. Network modeling reveals prevalent negative regulatory relationships between signaling sectors in Arabidopsis immune signaling. PLoS Pathol. 6:e1001011. Published online.

Segonzac, C., and Zipfel, C. 2011. Activation of plant pattern-recognition receptors by bacteria. Curr. Opin. Microbiol. 14:54-61.

Segonzac, C., Feike, D., Gimenez-Ibanez, S., Hann, D. R., Zipfel, C., and Rathjen, J. P. 2011. Hierarchy and roles of pathogen-associated molecular pattern-induced responses in Nicotiana benthamiana. Plant Physiol. 156:687-699.

Sinha, D., Gupta, M. K., Patel, H. K., Ranjan, A., and Sonti, R. V. 2013. Cell wall degrading enzyme induced rice innate immune responses are suppressed by the type 3 secretion system effectors XopN, XopQ, XopX and XopZ of Xanthomonas oryzae pv. oryzae. PLoS One 8:e75867. Published online.

Sonnewald, S., Priller, J. P., Schuster, J., Glickmann, E., Hajirezaei, M. R., Siebig, S., Mudgett, M. B., and Sonnewald, U. 2012. Regulation of cell wall-bound invertase in pepper leaves by Xanthomonas campestris pv. vesicatoria type three effectors. PLoS One 7:e51763. Published online.

Spoel, S. H., and Dong, X. 2012. How do plants achieve immunity? Defence without specialized immune cells. Nat. Rev. Immunol. 12:89-100.

Tai, T. H., Dahlbeck, D., Clark, E. T., Gajiwala, P., Pasion, R., Whalen, M. C., Stall, R. E., and Staskawicz, B. J. 1999. Expression of the Bs2 pepper gene confers resistance to bacterial spot disease in tomato. Proc. Natl. Acad. Sci. U.S.A. 96:14153-14158.

Thieme, F., Koebnik, R., Bekel, T., Berger, C., Boch, J., Buttner, D., Caldana, C., Gaigalat, L., Goesmann, A., Kay, S., Kirchner, O., Lanz, C., Linke, B., McHardy, A. C., Meyer, F., Mittenhuber, G., Nies, D. H., Niesbach-Klosgen, U., Patschkowski, T., Ruckert, C., Rupp, O., Schneiker, S., Schuster, S. C., Vorholter, F. J., Weber, E., Puhler, A., Bonas, U., Bartels, D., and Kaiser, O. 2005. Insights into genome plasticity and pathogenicity of the plant pathogenic bacterium Xanthomonas campestris pv. vesicatoria revealed by the complete genome sequence. J. Bacteriol. 187:7254-7266.

Thomma, B. P., Nurnberger, T., and Joosten, M. H. 2011. Of PAMPs and effectors: The blurred PTI-ETI dichotomy. Plant Cell 23:4-15.

Tsuda, K., and Katagiri, F. 2010. Comparing signaling mechanisms engaged in pattern-triggered and effector-triggered immunity. Curr. Opin. Plant Biol. 13:459-465.

Turner, P., Barber, C., and Daniels, M. 1984. Behavior of the transposons $T n 5$ and $T n 7$ in Xanthomonas campestris pv. campestris. Mol. Gen. Genet. 195:101-107.

Ustun, S., Bartetzko, V., and Bornke, F. 2013. The Xanthomonas campestris type III effector XopJ targets the host cell proteasome to suppress salicylic-acid mediated plant defence. PLoS Pathol. 9:e1003427. Published online.

van Wees, S. 2008. Phenotypic analysis of Arabidopsis mutants: Trypan blue stain for fungi, oomycetes, and dead plant cells. CSH Protocols 2008:pdb prot4982.

Wengelnik, K., VandenAckerveken, G., and Bonas, U. 1996. HrpG, a key hrp regulatory protein of Xanthomonas campestris pv. vesicatoria is homologous to two-component response regulators. Mol. PlantMicrobe Interact. 9:704-712.

Whalen, M. C., Wang, J. F., Carland, F. M., Heiskell, M. E., Dahlbeck, D., Minsavage, G. V., Jones, J. B., Scott, J. W., Stall, R. E., and Staskawicz, B. J. 1993. Avirulence gene avrRxv from Xanthomonas campestris pv. vesicatoria specifies resistance on tomato line Hawaii 7998. Mol. PlantMicrobe Interact. 6:616-627.

Xiang, T., Zong, N., Zou, Y., Wu, Y., Zhang, J., Xing, W., Li, Y., Tang, X., Zhu, L., Chai, J., and Zhou, J. M. 2008. Pseudomonas syringae effector AvrPto blocks innate immunity by targeting receptor kinases. Curr. Biol. 18:74-80

Zhang, J., Li, W., Xiang, T., Liu, Z., Laluk, K., Ding, X., Zou, Y., Gao, M., Zhang, X., Chen, S., Mengiste, T., Zhang, Y., and Zhou, J. M. 2010. Receptor-like cytoplasmic kinases integrate signaling from multiple plant immune receptors and are targeted by a Pseudomonas syringae effector. Cell Host Microbe 7:290-301.

Zuo, J. R., Niu, Q. W., and Chua, N. H. 2000. An estrogen receptor-based transactivator XVE mediates highly inducible gene expression in transgenic plants. Plant J. 24:265-273. 